\title{
Recent advances in offshore geotechnics for deep water oil and gas developments
}

Published in Ocean Engineering, 38: 818-834, 2011

http://dx.doi.org/10.1016/j.oceaneng.2010.10.021

\section{Mark F. RANDOLPH (corresponding author)}

Centre for Offshore Foundation Systems - M053

University of Western Australia

35 Stirling Highway, Crawley

Perth, WA 6009

Australia

Tel: +61 864883075

Fax: +61 864881044

Email: randolph@civil.uwa.edu.au

\section{Christophe GAUDIN}

Centre for Offshore Foundation Systems, University of Western Australia Perth, Australia

\section{Susan M. GOURVENEC}

Centre for Offshore Foundation Systems, University of Western Australia Perth, Australia

\section{David J. WHITE}

Centre for Offshore Foundation Systems, University of Western Australia Perth, Australia

\section{Noel BOYLAN}

Centre for Offshore Foundation Systems, University of Western Australia Perth, Australia

\section{Mark J. CASSIDY}

Centre for Offshore Foundation Systems, University of Western Australia Perth, Australia

No. of words: 8780 (without abstract and references)

No. of tables: 0

No. of figures: 28 


\begin{abstract}
:
The paper presents an overview of recent developments in geotechnical analysis and design associated with oil and gas developments in deep water. Typically the seabed in deep water comprises soft, lightly overconsolidated, fine grained sediments, which must support a variety of infrastructure placed on the seabed or anchored to it. A particular challenge is often the mobility of the infrastructure either during installation or during operation, and the consequent disturbance and healing of the seabed soil, leading to changes in seabed topography and strength. Novel aspects of geotechnical engineering for offshore facilities in these conditions are reviewed, including: new equipment and techniques to characterise the seabed; yield function approaches to evaluate the capacity of shallow skirted foundations; novel anchoring systems for moored floating facilities; pipeline and steel catenary riser interaction with the seabed; and submarine slides and their impact on infrastructure. Example results from sophisticated physical and numerical modelling are presented.
\end{abstract}

Key words: Geotechnical engineering, offshore engineering, in situ testing, shallow foundations, anchors, pipelines, submarine slides 


\section{Introduction}

The world's escalating demands for energy, combined with the continued depletion of oil and gas reserves in shallow waters, has resulted in offshore developments moving beyond the immediate continental shelf into deeper waters and untested environments. In the Gulf of Mexico, West Africa, offshore Brazil and more recently off Australia, developments have proceeded into water depths in excess of $1000 \mathrm{~m}$. These deep water developments usually consist of moored floating facilities, which are tethered to the seabed via an anchoring system. Hydrocarbons are transported to and from the seabed through vertical or catenary risers connected to a flowline or pipeline system. The complex subsea infrastructure comprises an integrated network of wells, manifolds and pipelines, all of which are supported by foundations.

\subsection{Scientific challenges}

The nature of geotechnical foundation design has changed radically for developments in deep water, compared to shallow water. This is partly due to the type of offshore facility (floating, or subsea) and partly because of the nature of the seabed sediments. There is reduced emphasis on traditional foundation systems such as piles and large gravity-base foundations; instead, anchor systems must be designed for floating facilities, so the anchors face a significant component of uplift load for taut and semi-taut mooring configurations. In response, new anchoring systems have evolved, such as suction caissons, plate anchors (either suction embedded or dragged in) and dynamically embedded torpedo anchors (which are simply dropped into the seabed). 
Geotechnical design is also increasingly focused on pipeline and riser interactions with the seabed, and on the design of efficient shallow skirted foundations and mats for wellhead manifolds and pipeline termination structures.

Major scientific challenges within deep water geotechnical engineering include the following:

Characterising soil in remote locations: Deep water sites consist typically of soft finegrained sediments (either clay, or in some regions carbonate muds and silts) that have been deposited relatively slowly and are characterised by increasing strength with depth. Handling samples of these soft soils is extremely difficult, so in situ testing is preferable, increasingly with full-flow penetrometers. Characterisation of the seabed sediments is therefore challenging, particularly for design of pipelines, steel catenary risers and manifolds where only the upper one or two metres are of interest and strengths are generally very low. Site investigations must also extend over a wide spatial area. Anchoring locations are typically kilometres apart and pipeline routes can extend for hundreds of kilometres. BP's Greater Plutonio development off West Africa (in $1350 \mathrm{~m}$ of water) represents a typical field layout (Figure 1).

Mobile infrastructure: Traditional soil mechanics is focused on ensuring the stability and serviceability of stationary foundations under working loads. However, static design is not always applicable in deep water applications: the geotechnical infrastructure may be designed to allow movement. Examples include controlled lateral buckling of pipelines (due to operational temperature and pressure changes), trench development of steel catenary risers (SCRs) and the installation of drag and plate anchors. All of these 
situations involve quantifying the changing soil resistance and kinematics for structural components moving distances exceeding their size.

Changing soil properties: The episodic nature of offshore cyclic loading can cause significant changes in soil strength and stiffness of more than an order of magnitude due to disturbance, remoulding, reconsolidation and water entrainment. The recovery of soil strength through reconsolidation can be as significant as the reduction in strength when remoulding is imposed. Another challenging example is determining the evolution of soil properties within a landslide run out or 'debris flow' that may impact deep water facilities down slope of the continental shelf break.

Fatigue based design: Cumulative fatigue damage under cyclic loading at low frequency (wave driven) and high frequency (current driven vortex induced vibration) has become the dominant design consideration in many deep water applications, such as riser towers, top-tensioned risers, SCRs and pipelines with long spans. This places emphasis on the stiffness of the foundation response rather than ultimate capacity.

\subsection{Aim of the paper}

This paper provides a review of the challenges facing geotechnical engineers as they design oil and gas infrastructure for deep water applications. It follows a broader review of offshore geotechnics published as an invited state of the art report at the $16^{\text {th }}$ International Conference on Soil Mechanics and Geotechnical Engineering (Randolph et al., 2005), and a more recent report focusing on deep water geotechnical engineering (Andersen et al., 2008). It aims to provide an update of the contemporary research contributions to deep water geotechnics. Due to space limitations the paper concentrates on contributions to the design of mudmats, anchoring systems, pipelines and risers, as 
well as reviewing recent understanding of offshore landslides and the interaction forces with pipelines. A detailed review of offshore geotechnical engineering in general can be found in Randolph and Gourvenec (2010).

Physical modelling and numerical analysis tools have also advanced, to tackle challenges of deep water. Within the geotechnical centrifuge, for instance, accurate motion control techniques are now able to replicate complex cyclic loading sequences, and novel visualisation techniques can reveal the failure mechanisms of mobile foundations, pipelines and anchors (Gaudin et al., 2010a, b). Large deformation finite element analysis has also provided numerous insights into the behaviour of deep water infrastructure (Randolph et al., 2008).

\section{Site Investigation Techniques}

The majority of site investigation in deep water uses seabed-based equipment in order to minimise disturbance of the soft sediments. Samples are recovered using large diameter piston coring equipment such as the jumbo piston corer (Young et al., 2000) and STACOR sampler (Borel et al., 2002, 2005), where the piston is (nominally) held fixed relative to the seabed as the corer advances under gravity. These devices have a steel barrel, with typically a 90 to $130 \mathrm{~mm}$ diameter PVC liner. They penetrate the seabed under their own weight, and can retrieve samples up to 20 to $30 \mathrm{~m}$ long. Recovery rates in excess of 90 per cent can be achieved, although there is always some uncertainty in respect of precisely where the piston is arrested, and hence the depth of the uppermost soil sampled. If the surface sediments are soft, the base plate of the STACOR may penetrate $0.5 \mathrm{~m}$ or so before it, and hence the piston, come to rest. 
In situ testing is carried out using a seabed frame with in-built continuous penetrometer rods (either coiled or suspended from the vessel under tension), and advanced into the seabed by a wheel-drive system. Vane testing and shallow sampling may also be achieved from a seabed system, to depths of 30 to $40 \mathrm{~m}$. Shallow samples, up to $1.5 \mathrm{~m}$ long, may also be recovered using seabed frames, and an alternative approach for shallow strength profiling is to perform miniature penetrometer tests and vane tests in box cores on the vessel (Low et al., 2008).

More sophisticated robotic seabed-based systems such as the PROD (portable remotely operated drill - www.benthic.com.au) and ROVDRILL (www.sfgeoservices.com) have been developed over the last decade. A photograph of the second generation PROD, recently commissioned, is shown in Figure 2. These devices, which are connected to the surface vessel via an umbilical, are able to drill, take samples (storing them on a carousel) and conduct penetrometer tests to depths of up to $100 \mathrm{~m}$, with typical push lengths for penetrometer testing of 2 to $3 \mathrm{~m}$.

In soft deep water sediments, although cone penetrometer testing is still used as the basic stratigraphic investigation tool, shear strength determination relies increasingly on full-flow T-bar (cylindrical) and ball (spherical) penetrometers (Randolph, 2004; Randolph et al., 2007) - see Figure 3. The principle behind these devices is that the projected area of the penetrometer head is 5 to 10 times greater than the cross-sectional area of the shaft. This reduces the correction for pore pressure acting on the load cell seals, or for overburden pressure, by an order of magnitude, which is an important advantage in sediments with a low strength ratio $\left(\mathrm{s}_{\mathrm{u}} / \sigma_{\mathrm{v} 0}^{\prime}\right)$. 
Although the T-bar is more widely used and has the advantage that it has the same geometry as an element of pipeline, the ball penetrometer has a simpler geometry and allows incorporation of pore pressure filters at different locations, as indicated in Figure 4 (see also Boylan et al., 2007; DeJong et al. 2008). This allows assessment of consolidation characteristics by means of dissipation tests. Experience shows that, for a given diameter, the time-scale for consolidation is about three times faster than for the piezocone (Low et al., 2007).

Another advantage of full-flow penetrometers compared with the cone penetrometer is the ability to measure the remoulded shear strength in situ, in addition to the intact shear strength, by means of cyclic penetration and extraction tests conducted over a limited depth range (Randolph, 2004). An example from the Norwegian onshore test site at Onsøy is shown in Figure 5. In box-cores, or centrifuge model tests, it is possible to perform a sequence of cyclic loading episodes, leading to full remoulding, followed by intervals sufficiently long to allow full consolidation, thereby allowing the gain in strength due to reconsolidation to be assessed (White \& Hodder, 2010). Evaluation of the remoulded shear strength, sensitivity and setup of shallow seabed sediments is of particular importance for pipeline and riser design.

Plasticity solutions have been developed for the penetration resistance of cylindrical and spherical objects (Randolph and Houlsby, 1984; Randolph et al., 2000; Einav and Randolph, 2005; Martin and Randolph, 2006). In practice, however, the resistance factor has been shown to be affected significantly by the strain rate dependency of the soil strength, and also by the gradual softening (due to remoulding) that occurs as the soil is disturbed by the passage of the penetrometer. This has been modelled by expressing the soil shear strength as (Einav and Randolph, 2005): 


$$
\left.\mathrm{s}_{\mathrm{u}}=\left[1+\mu \log \left(\frac{\max \left(\left|\&_{\text {max }}\right|, \&_{\mathrm{ref}}\right)}{\&_{\mathrm{ref}}}\right)\right]\left[\delta_{\text {rem }}+\left(1-\delta_{\text {rem }}\right) \mathrm{e}^{-3 \xi / \xi_{95}}\right]\right]_{\mathrm{u} 0}
$$

where:

$$
\begin{aligned}
& \mu \quad=\text { logarithmic rate dependency parameter; } \\
& \&_{\text {max }}=\text { local maximum shear strain rate; } \\
& \&_{\text {ref }} \quad=\text { reference shear strain rate; } \\
& \delta_{\text {rem }}=\text { remoulded strength ratio (inverse of sensitivity, } \mathrm{S}_{\mathrm{t}} \text { ); } \\
& \xi \quad=\text { cumulative octahedral plastic shear strain; } \\
& \xi_{95} \quad=\text { value of } \xi \text { required for } 95 \% \text { remoulding; } \\
& \mathrm{Su}_{\mathrm{u} 0} \quad=\text { intact reference shear strength. }
\end{aligned}
$$

Values of the T-bar resistance factor, $\mathrm{N}_{\text {Tbar, }}$ obtained from large deformation finite element analysis are shown in Figure 6 as a function of $\mu$ for a range of $\xi_{95}$ values (which determine the relative brittleness of the soil strength), for soil with sensitivity of 5 (hence $\delta_{\text {rem }}=0.2$ ). It may be seen that, for a typical rate dependency factor of $\mu=0.1$, intermediate values of $\xi_{95}$ yield $\mathrm{N}_{\text {Tbar }}$ value of 10.5 to 12 . This range is in accordance with field experience, where a worldwide database led to an overall average factor of 12 (relative to laboratory shear strengths from simple shear tests, or the average from triaxial compression, simple shear and triaxial extension tests) (Low et al., 2010).

The database reported by Low et al. also indicated little difference (in the range 0 to $10 \%$ ) between the penetration resistance of T-bar and ball penetrometers, which contrasts with numerical predictions that typically show the ball resistance being some $20 \%$ higher than the T-bar resistance. The average field correlation factor of 12 is a little higher than the value of 10.5 commonly adopted in centrifuge modelling practice 
(Gaudin et al., 2010a) and probably reflects higher strain rate dependency of offshore sediments, at least in the high plasticity clays offshore West Africa. In regions with seabed sediments of lower plasticity, a T-bar factor of around 11 may prove more appropriate.

Interpretation of cyclic full-flow penetrometer tests comprises plotting the penetration and (absolute) extraction resistance at mid-cycle against the number of cycles. Randolph et al. (2007) have argued that the cycles should be numbered from 0.25 for the first penetration stage, 0.75 for the first extraction stage and so forth, as indicated in Figure 7. The relative penetration resistance for the $\mathrm{i}^{\text {th }}$ cycle may be estimated by (Zhou and Randolph, 2009b):

$$
\mathrm{N}_{\text {cyclei }}=\left(\delta^{\prime \prime}{ }_{\text {rem }}+\left(1-\delta^{\prime \prime}{ }_{\text {rem }}\right) \mathrm{e}^{-3(2 \mathrm{i}-0.5) \xi_{\mathrm{k}} / \xi_{95}}\right) \mathrm{N}_{\text {cycle } 0.25}
$$

where $\delta "$ rem is the ratio of the final cyclic penetration resistance, after full remoulding, to the initial penetration resistance. As they note, the 'penetration sensitivity' (inverse of $\delta "$ rem) is less than the intrinsic sensitivity of the soil, so that the resistance factor for fully remoulded conditions is greater than that for intact conditions. Low et al. (2010) quote resistance factors for fully remoulded conditions ranging from 15 (relative to strengths deduced from fall cone tests) to 20 (strengths from remoulded UU tests).

Recommended practices for conducting in situ full-flow penetrometer tests have been suggested recently by DeJong et al. (2010) and Lunne et al. (2010). Among the various recommendations are to (a) include at least one cyclic stage in each penetrometer test, to help interpret the intact penetration resistance and confirm the load cell zero offset; and (b) to standardise on 10 full cycles in order to measure the remoulded resistance. The 
value of 10 cycles is proposed as a practical compromise in order to limit the duration of the cyclic test, while still achieving approximate full remoulding of the soil.

The low shear strength of most deep water seabed sediments has shifted the focus from the laboratory to the ocean floor, not just for assessing the shear strength profile but also in respect of conducting model tests in situ. This shift is discussed in more detail later in relation to the SMARTPIPE development (Hill and Jacob, 2008), but it is also evident in the thinking behind the companion SMARTSURF tool (Puech et al., 2010).

\section{Shallow Foundations for Deep Water}

\subsection{Shallow foundations for subsea infrastructure}

Small shallow foundations are used widely in deep water environments to support subsea infrastructure, such as pipeline end manifolds and terminations (PLEMs and PLETs), pipeline sleepers and protection systems. They may rest directly on the seabed, but are usually provided either with short ribs or with peripheral (and internal) foundation skirts, such as shown in Figure 8 for a foundation system to support a subsea frame. The foundations are typically rectangular, with breadths from $2-10 \mathrm{~m}$, length to breadth aspect ratios in the region of 2:1 and embedment (or skirt) depth to breadth ratios up to 0.5 , but more typically 0.05 to 0.2 .

Shallow foundations for subsea structures are smaller than their counterparts for fixed bottom structures that extend through the water column, but the loads transmitted to the foundation system are often more complex. The dominant loads are horizontal $(\mathrm{H})$ and torsional (T), with relatively low vertical loads (V), contrasting with platform foundations where relatively higher vertical loads must be withstood in combination with significant horizontal load $(\mathrm{H})$ and overturning moment $(\mathrm{M})$. Infrastructure 
connections and environmental loads can lead to significant non-zero components of $\mathrm{H}_{\mathrm{x}}$, $H_{y}, M_{x}, M_{y}$ and $T_{z}$, in conjunction with the vertical dead load of the foundation system and structure, leading to full 6 degree-of-freedom loading.

Current methods for accounting for co-planar horizontal loads, biaxial moments and torsion are rudimentary (e.g. DNV, 1992; API, 2000; ISO, 2003). Attention is shifting towards a failure envelope approach to determine ultimate limit states. This approach has experienced increasing acceptance in recent years for prediction of ultimate limit states for shallow foundations under general loading. An annex on the failure envelope approach was included in the recent API RP 2 Geo (issued for ballot in 2010), which covers geotechnical design for both shallow and pile foundations (Jeanjean et al., 2010). This marks a significant shift in a design methodology that has been established for over 50 years.

Figure 9 shows an example of a failure envelope for general VHM capacity of rectangular surface foundations. The principle is that a load state that lies within the envelope is safe while a load state that lies outside the envelope results in foundation failure. The failure envelope has many advantages over the conventional bearing capacity theory found in design guidelines. The key advantages of the failure envelope approach are explicit consideration of the independent load components and a graphical interpretation of the factor of safety associated with different load paths. The failure envelope method is also conducive to explicit consideration of foundation geometry and soil conditions rather than superposing modification factors for shape, embedment and soil strength heterogeneity. 
Most failure envelopes that are available for routine design address VHM loading (Ukritchon et al., 1998; Bransby and Randolph, 1998; Taiebat and Carter, 2000, 2010; Gourvenec and Randolph, 2003; Gourvenec 2007a, b). Attention has focused on HT and VHT loading (Murff and Miller, 1977; Finnie and Morgan, 1994; Yun et al., 2009; Murff et al., 2010) and sparse literature is available on 6 degree-of-freedom loading (Byrne and Houlsby, 2005; Cassidy and Cheong, 2005; Bienen et al., 2006, 2007) although a failure envelope for routine use for shallow foundations in deep water has yet to be established.

\subsection{Shallow foundation design for uplift loading}

Shallow skirted foundations potentially provide an alternative to tension piles or suction caissons for mooring buoyant facilities. Clusters of four concrete 'buckets', i.e. skirted foundations penetrating between 4 and $12 \mathrm{~m}$ (5 to $20 \%$ of the overall foundation width) into the seabed, were used successfully to moor two tension leg platforms (TLPs) in the North Sea: Snorre A and Heidrun (St $\phi v e$ et al. 1992) in up to 350 m water depth (see Figure 10). In those cases the weight of the foundation system, augmented by ballast, counteracted the tension in the tethers under normal working conditions. Only under storm conditions were skirt friction and passive suctions under the top cap relied on to resist the additional loads incurred as the platform was offset relative to the foundation system. However, shallow skirted foundations can provide more cost-effective foundation solutions in deeper waters by relying on some sustained tensile resistance under normal working conditions. 
Critical design questions that need to be answered if passive suctions are to be relied on in foundation design are: what degree of reverse end bearing can be mobilised, and if so, for how long can passive suctions be relied on?

Passive suctions (i.e. negative excess pore pressures) are developed beneath the top cap of a skirted foundation during undrained uplift (either from buoyancy loads or overturning moments). While passive suctions can be maintained, uplift failure will be governed by reverse end bearing (i.e. a conventional compression failure but in reverse). A hydraulic gradient is set up between the water pressure inside and outside the foundation and with time (the duration depending on the permeability of the soil and the drainage path length), water will flow into the soil plug from the surrounding soil and the passive suctions will dissipate. In the absence of passive suctions, uplift capacity is reduced to the sum of the external skirt friction and the lesser of internal friction or the weight of the soil plug - potentially an order of magnitude less than the reverse end bearing capacity. Pore pressure dissipation around shallow foundations (surface, buried and skirted) has been considered recently through finite element analysis (Gourvenec and Randolph, 2009, 2010). Full consideration of pore pressure effects on uplift capacity is complex and an active area of research. Gapping along the skirt-soil interface will short-circuit the drainage path with a detrimental effect on uplift capacity.

The transition of uplift capacity from undrained to drained conditions can be conveniently represented as a time history of the available uplift resistance as a fraction of the undrained uplift capacity. Results from centrifuge model tests of shallow skirted foundations with normalised skirt depth $d / D=0.3$ (where $d$ is the skirt penetration and $\mathrm{D}$ the diameter of the foundation), under transient and sustained uplift are shown in Figure 11 (Gourvenec et al., 2009; Acosta-Martinez et al., 2010). A bearing capacity 
factor $\mathrm{N}_{\mathrm{C}} \sim 9$ was mobilised when undrained reverse end bearing governed failure, and notably a similar capacity was still achieved when uplift was applied immediately following the deliberate formation of a gap between the foundation skirts and the soil on one side of the foundation. When a time delay was allowed between gap formation and uplift, softening of the soil and a shortening of the drainage path led to a local shear failure, with the foundation simply pulling out of the soil, leaving the soil plug in place. A reduction in uplift resistance of $\sim 50 \%$ resulted.

Load eccentricity had a detrimental effect on uplift capacity, although a reverse end bearing mechanism is indicated by the shape of the load-displacement paths, with gradual mobilisation of resistance with increased displacement. Figure 11b shows that uplift loads of $20 \%$ of the undrained uplift resistance may be resisted for up to several years with minimal displacements (w/D $<2 \%$ ) if nominal contact is maintained along the foundation-soil interface. Gapping along the skirt-soil interface led to an order of magnitude reduction in holding time for the same load and displacement criteria although uplift resistance was still sustained for several months. Further investigation, through centrifuge modelling and advanced numerical analysis, is required to quantify the mechanisms governing transient and sustained uplift resistance of shallow foundations under general loading.

\section{Anchoring Systems}

\subsection{Suction caissons}

Suction caissons are large diameter steel cylinders, open-ended at the bottom and closed at the top, typically 5 to $25 \mathrm{~m}$ long and with a length to diameter ratio $\mathrm{L} / \mathrm{D}$ in the range three to six. They were first used in the North Sea as anchors for a catenary anchor leg mooring in the Gorm 
field (Senpere and Auvergne, 1982) and nowadays are the most widely used anchor for floating facilities in deep water. A well documented example is the Na Kika semi-submersible FPS in the Gulf of Mexico, which is moored in 1,920 m depth of water by 16 suction caisson anchors, $4.3 \mathrm{~m}$ diameter and $25.3 \mathrm{~m}$ long (Newlin, 2003). In addition to use as anchors, they are also used extensively for pipeline manifolds and end terminations, and also as the foundation for riser towers.

Suction caissons are now a mature product, with well developed analysis procedures covering both installation (by self-weight followed by suction, or under pressure) and loading (Andersen et al., 2005; Randolph et al., 2005). Early applications were for catenary mooring systems where the operational loading was at a relatively shallow angle to the horizontal, and the focus of analysis was on the lateral capacity and optimising the depth of the padeye to limit rotation of the caisson as it failed, hence maximising the capacity. Attention here is limited to the uplift capacity of suction caissons, which is critical for modern semi-taut and taut mooring systems (including top-tensioned risers where the loading is quasi-vertical).

Typically the uplift capacity of a suction caisson, assuming fully sealed conditions (i.e. with reverse end-bearing mobilised at the base of the caisson) will not exceed 50 to $60 \%$ of the horizontal capacity. The uplift capacity therefore becomes critical once the angle of loading exceeds about $30^{\circ}$ above the horizontal, as is the case for semi-taut and taut moorings. The thin-walled nature of suction caissons, with diameter (D) to wall thickness (t) ratios exceeding 150, leads to lower radial stresses being generated during installation compared with a typical open-ended pile (with D/t typically 40). As such, and also because of the suction applied during installation, the external friction has been found to be some $20 \%$ lower than would be assumed for a driven pile (Andersen and Jostad, 2002, Chen and Randolph, 2007a; Chen et al., 2009). Model tests using double-walled caissons have shown that the end-bearing mobilised at the point of peak shaft friction is equivalent to a bearing factor of $\mathrm{N}_{\mathrm{c}} \sim 9$, even though the endbearing may still be rising (Jeanjean et al., 2006). 
Suction caissons are commonly designed so that permanent uplift loads may be taken adequately by external friction and the weight of the caisson and internal soil plug, relying on reverse end-bearing only for transient loading (Andersen et al., 2005). In certain situations, however, environmental loading may be sustained over days or even weeks. Several testing programs have investigated suction caisson performance under cyclic and sustained loading, and these have tended to show little degradation from cyclic loading and an ability to withstand at least $80 \%$ of the short term capacity over several months (Randolph and House, 2002; Clukey and Phillips, 2002; Chen and Randolph, 2007b). Numerical studies support these findings, indicating a minimum sustained capacity of about $70 \%$ of the short term uplift capacity (Clukey et al., 2004).

Two factors may reduce the sustained uplift capacity. The first of these is the time taken for the full capacity to be developed following installation, as thixotropy and consolidation occur. Field data suggest that full set-up is generally achieved in Gulf of Mexico soils after about 100 days, with $50 \%$ improvement in capacity after 5 to 10 days (Jeanjean, 2006). The second factor is the integrity of the internal seal provided by the soil plug. This may be compromised, and the internal shaft resistance reduced, if ring stiffeners are used on the inside of the caisson (Andersen and Jostad, 2004; Andersen et al., 2005).

\subsection{Suction embedded plate anchors}

The suction embedded plate anchor (SEPLA) incorporates the advantages of a conventional suction caisson, namely: proven installation methods along with known position and penetration depth; together with the benefits of a vertically loaded anchor (VLA) (Figure 12), namely: low cost and the ability to efficiently handle a high vertical load (Wilde et al., 2001). Prior to 2004, SEPLAs were limited to temporary moorings for MODUs (mobile drilling units). The first permanent application was installed in 2006 for a floating production unit in the Gulf of Mexico (Rigzone, 2006). Today the anchor is commonly used in deep waters. 
The SEPLA concept borrows installation techniques from conventional suction caissons. A modified caisson known as a follower houses a plate anchor inserted in a vertical slot at the base. During installation, the follower and plate anchor are installed to the design depth in the same manner as a suction caisson. Water is then pumped into the top of the follower to retrieve it for re-use. The plate anchor remains oriented vertically at the design depth.

Following installation, the plate must be rotated from its vertical position towards an inclination normal to the load applied by the mooring line (Dove et al., 1998). This process is known as keying and it exposes the maximum cross-sectional area of the anchor to the loading direction, maximising the bearing capacity. This is conducted offshore with minimal delay and by tensioning the mooring line and loading the anchor to typically 20 to $30 \%$ of its maximum holding capacity. During the keying process, the anchor experiences vertical motion, resulting in a loss of embedment.

The challenge in estimating anchor capacity is more in prediction of the keyed embedment, than in estimating the bearing factor, which numerical and experimental analysis has shown to be in the range 11 to 12 for deeply embedded rectangular anchors (Randolph et al., 2005). In typical seabeds with strength increasing almost proportionally with depth, the loss of embedment during keying may result in a reduction in capacity of up to $20 \%$.

Loss of embedment during keying has been extensively investigated experimentally (O’Loughlin et al., 2006; Song et al., 2009) and numerically, using large deformation finite element (LDFE) analysis (Song et al., 2008; Wang et al., 2010a). The latter notably included the anchor-chain interaction, adjusting the load inclination at the padeye as the chain is tensioned.

Numerical results, validated by experimental data, show the importance of the padeye eccentricity, the anchor thickness and the weight of the anchor in soft soil. These variables influence the moment loading on the anchor, particularly prior to the point where the vertical 
component of load balances the anchor weight. High moment load encourages rotation of the anchor instead of vertical motion, thus reducing the embedment loss.

Relationships for the loss of embedment have been derived by Wang et al. (2010a), from LDFE analysis, in a systematic way based on the relevant non-dimensional groups of the anchor and soil parameters. For typical SEPLA weights and geometry, the loss of embedment under vertical pullout was found to range from 0.6 to 1 times the anchor height, which is in good agreement with experimental data (O’Loughlin et al., 2006), but in the lower range of data from field trials (Wilde et al., 2001). SEPLAs are typically loaded at an inclination of around 40 degrees from horizontal at the mudline. The influence of the load inclination on the loss of embedment has been investigated numerically (Wang et al., 2010a) and experimentally (Gaudin et al., 2008, 2010c). In all cases, the loss of embedment was found to decrease linearly with the reduction of load inclination to the horizontal. Therefore, for typical loading conditions, this would reduce the loss of embedment to 0.4 to 0.6 times the anchor height.

More recently, the performance of a keying flap (see Figure 12) was investigated by Gaudin et al. (2010c). This device is designed to reduce the loss of embedment by activating (rotating) as the anchor moves vertically, impeding further vertical motion. Centrifuge tests, combined with PIV analysis (White et al. 2003) demonstrated that the flap does not rotate during keying, so does not affect the embedment loss (Figure 13). The non-activation is explained by the rotation of the anchor, which results in increased soil pressure acting on the back of the flap, locking it in place. This finding may lead to revised anchor designs, since most SEPLAs currently feature a keying flap.

\subsection{Dynamically penetrating anchors}

Dynamically penetrating anchors, or 'torpedo' anchors, are a cost-effective solution for anchoring mobile drilling offshore units. They are rocket-shaped, typically 12 to $15 \mathrm{~m}$ long and 0.8 to $1.2 \mathrm{~m}$ in diameter, with a dry weight of 500 to $1000 \mathrm{kN}$, and may feature up to four flukes 
at the trailing edge (Figure 14). They are released from a height of 50 to $100 \mathrm{~m}$ from the seabed, achieving velocities up to $30 \mathrm{~m} / \mathrm{s}$, and embedding by up to 3 times their length. Initial use of torpedo anchors took place in the Campos Basin (Medeiros, 2001, 2002). A similar concept has also been used in European waters (Lieng et al., 1999, 2010) and in the Gulf of Mexico (Zimmerman et al., 2009).

Challenges associated with dynamically penetrating anchors include prediction of the anchor embedment depth and the subsequent capacity. The former is complicated by the very high strain rate (in the order of $25 \mathrm{~s}^{-1}$ ) at the soil anchor interface, resulting from the high penetration velocities, and hydrodynamic aspects related to possible entrainment of a boundary layer of water adjacent to the anchor (O’Loughlin et al., 2009).

Consequently, prediction methods for anchor embedment depth combine a fluid mechanics drag component (important at shallow penetration) with conventional geotechnical friction and bearing resistance but accounting for the strain-rate enhanced shear resistance via a rate parameter (Audibert et al., 2006, O' Loughin et al., 2009). The rate parameter $\mathrm{R}_{\mathrm{f}}$ is expressed as a logarithmic or power law expression according to:

$$
\mathrm{R}_{\mathrm{f}}=1+\lambda \log \left(\frac{\&}{\&_{\text {ref }}}\right) \text { or } \mathrm{R}_{\mathrm{f}}=\left(\frac{\&}{\&_{\text {ref }}}\right)^{\beta}
$$

where $\lambda$ and $\beta$ are rate parameters and $\&$ the strain rate, which may be taken, as a first approximation, as the ratio of the penetration velocity $\mathrm{v}$ to the diameter $\mathrm{d}$ of the anchor.

Limited field data are in the public domain to calibrate prediction methods and determine values of the rate parameter $R_{f}$ and the drag coefficient $C_{d}$. Most of the contributions arise from centrifuge modelling studies performed on kaolin clay (O’Loughlin et al., 2004, 2009; Richardson et al., 2005, 2006), although an expanding database of field performance is emerging (Zimmerman et al., 2009; Lieng et al., 2010). 
Figure 15 presents best values of the rate coefficients, $\lambda$ and $\beta$ characterising the rate of increase in strength with nominal strain rate, $\mathrm{v} / \mathrm{d}$, for various drop heights, including or omitting the drag coefficients $C_{d}$, taken here as 0.24 . Values for $\lambda$ and $\beta$ are significantly higher than the nominal $10 \%$ increase in shear strength per log cycle of strain rate typically found from laboratory shear tests. This rate augment may not apply at the very high strain rates generated by anchor penetration, which are about 10 orders of magnitudes higher than typical laboratory strain rates.

The pullout capacity of dynamically penetrating anchors has been investigated experimentally through centrifuge model testing (O’Loughlin et al., 2004; Richardson et al., 2006, 2009) and numerically (de Aguiar et al., 2009; Sagrilo et al., 2010), with limited results from field trials also being available. Results indicate that simple bearing capacity calculations summing endbearing and shaft resistance are appropriate for the vertical component of the anchor holding capacity, provided that the embedment (and hence the local soil strength) is accurately predicted. The holding capacity, for a given embedment, increases with the number of flukes due to the higher contact area (O'Loughlin et al., 2004; de Aguiar et al., 2009) and reduces as the pullout inclination rises from the horizontal (de Aguiar et al., 2009). As for suction caissons, once the load inclination exceeds about $30^{\circ}$ to the horizontal, the capacity is governed entirely by the vertical capacity.

Centrifuge work by Richardson et al. (2009) focused on the soil strength recovery after installation and the subsequent holding capacity (Figure 16). As the anchor penetrates at high velocity, significant soil disturbance is generated around the anchor and consolidation leads to an increase of anchor capacity with time, analogous to pile set-up. Results demonstrated a significant increase of capacity with time (by a factor of 5 from immediate extraction to full consolidation) but a greater period (up to 7 years for the $1.2 \mathrm{~m}$ diameter anchor presented here) was required to achieve full consolidation compared with equivalent piles or suction caissons. 
To increase anchor capacity, regardless of the achieved penetration embedment, improvements have been undertaken regarding the location of the anchor padeye, such as for the OMNI-Max anchor (Shelton, 2007; Zimmerman et al., 2009). In contrast to typical dynamically penetrating anchors, the OMNI-Max anchor features an arm that transfers the loading point nearer to the head of the anchor (see Figure 17). This configuration forces the anchor to dive deeper when pulled, gradually increasing the capacity. This is illustrated in Figure 18 with results of model tests in transparent artificial soil. As the anchor dives deeper the geotechnical resistance increases and the capacity is eventually governed by the tension capacity of the mooring line. Field evidence for this behaviour was obtained from anchor recoveries following overloading of MODU anchors during Hurricane Gustav in the Gulf of Mexico. Increases in embedment from 16 to $17 \mathrm{~m}$ at installation to in excess of 30 to $35 \mathrm{~m}$ were reported (Zimmerman et al., 2009).

\section{$5 \quad$ Pipelines and Risers}

\subsection{Pipelines}

Offshore pipelines are often left unburied on the seabed, if this does not lead to unacceptable instability under hydrodynamic loading, or if burial for protection from trawl gear is not required. Pipeline-seabed interaction feeds into many aspects of the pipeline design. If the pipeline must be buried, the shielding of the pipeline via the construction of a trench - which may be backfilled - requires geotechnical design.

On-bottom pipelines are increasingly being designed to allow movement during their operation, either under hydrodynamic loading or under thermal and pressure-induced expansion. Steel catenary risers, which are extensions of pipelines that connect to surface facilities, inevitably move where they touchdown on the seabed, in response to oscillation of the floating facility. 
One of the most difficult aspects of pipeline design, which is an increasing challenge as operating temperatures and pressures rise, is the management of thermal and pressureinduced loading. Controlled on-bottom lateral buckling - in which a pipeline might sweep laterally by 10 or 20 diameters across the seabed - is an attractive design solution (Figure 19). However, it requires the pipe-soil response - in a form analogous to p-y modelling of lateral pile behaviour - to be bracketed: both high and low geotechnical resistance can hamper a design (Bruton et al., 2007).

A second and related behaviour is the tendency for pipes to 'walk' axially over cycles of startup and shutdown (Tørnes et al., 2000; Carr et al., 2006). This phenomenon can be driven by the asymmetry of the heat-up and cool-down processes or by the presence of a seabed slope or end-of-line tension (which creates an asymmetry in the mobilized axial pipe-soil resistance). Accurate assessment of the axial pipe-soil resistance - in a manner analogous to the t-z modelling of pile shaft resistance - is required for robust modelling of this process.

Analogies can be made between pile and pipeline behaviour, and previous geotechnical research related to pile behaviour can often be usefully applied to pipelines. However, the underlying soil behaviour relevant to pipe-soil interaction often differs from that for pile-soil interaction, due to the low stress level, low rates of loading and the episodic nature of the movement. The stresses applied by pipelines are typically 1 to $5 \mathrm{kPa}$; axial expansions can take place as slowly as a fraction of a millimetre per second, but may involve several metres of movement; the pipe may then remain stationary for months, then reverse back towards the original position on shutdown. A further complication is the gross disturbance of the seabed when a pipeline sweeps laterally, scraping material away and remoulding it (Figure 19). 
Techniques are under development to characterise the pipe-soil response in deep water. These include theoretical solutions for pipeline embedment and breakout and new techniques to characterise the pipe-soil response - in particular the axial resistance - in situ at the seabed.

A critical first step in quantifying pipe-soil resistance is to assess the as-laid pipeline embedment. Theoretical solutions based on plasticity limit analysis have been established for pipelines at shallow embedment under combined vertical and horizontal loading (Randolph and White, 2008a). These results have been validated both by experimentally observed failure mechanisms and also complementary numerical analyses (Dingle et al., 2008; Zhou et al., 2008; Merifield et al., 2008; Wang et al. 2010b) (Figure 20).

The as-laid embedment of a pipeline is strongly influenced by the dynamic motion of the pipe as it comes into contact with the seabed. This motion depends on the laying geometry as well as the prevailing metocean conditions and the response of the lay vessel, and will lead to remoulding of the seabed soil and possibly water entrainment, which may reduce soil strength beyond the undrained remoulded value. It is inevitable that predictions of the as-laid embedment of a pipeline involve uncertainty due to these dynamic lay effects.

To quantify this uncertainty in embedment, and the likely variability in the subsequent lateral breakout resistance, the theoretical pipe-soil interaction solutions can be applied in a Monte Carlo analysis (White and Cathie, 2010). The natural variability of the seabed soil, as well as the uncertain changes caused by dynamic lay effects, can be assigned a statistical distribution. A Monte Carlo analysis then leads to the variation in 
breakout resistance and as-laid embedment. Figure 21 shows results arising from theoretical calculations using two independent distributions of remoulded strength (to assess the as-laid embedment) and reconsolidated strength (to assess the breakout resistance). In both cases the upper bound $\left(\mathrm{P}_{95}\right)$ and lower bound $\left(\mathrm{P}_{5}\right)$ strengths differed by a factor of 2. Interestingly, the resulting span between the $\mathrm{P}_{5}$ and $\mathrm{P}_{95}$ values of equivalent breakout friction factor, $\mathrm{H}_{\mathrm{brk}} / \mathrm{V}$, is only 1.5. This narrowing arises because pipe-soil breakout resistance does not scale directly with soil strength. In softer soil, the pipe embeds deeper, leading to increased passive resistance, which counteracts the influence of the reduced strength. A Monte Carlo approach quantifies this effect, with the pleasing outcome that soil strength uncertainty is attenuated when converted into ultimate pipe-soil resistance.

Probabilistic approaches are particularly useful for pipe-soil interaction. It is often necessary to assess both high and low limits of ultimate pipe-soil resistance. However, high and low breakout resistance does not necessarily correlate with high and low soil strength, again because of the compensating effect of increasing embedment in softer soil. Often the extreme values of breakout resistance result from intermediate values of soil strength, rather than extremes (White and Cathie, 2010).

To aid the assessment of pipe-soil interaction, new site investigation tools have been developed. One such tool is the Fugro SMARTPIPE: a seabed frame equipped with an instrumented model pipe (Hill and Jacob, 2008; White et al., 2010). The system can operate in deep water, measuring pipe-soil interaction forces in the vertical, lateral and axial directions, supported by detailed pore pressure data around the pipe periphery (Figure 22). 
The consolidation characteristics of the seabed can be identified via the pore pressure dissipation after placement of the SMARTPIPE on the seabed (Gourvenec and White, 2010; Krost et al., 2010). The pore pressure data also allows the axial response to be interpreted based on effective stresses, which provides a consistent trend through tests conducted at a range of speeds, and with varying levels of remnant excess pore pressure following initial embedment (White et al., 2010). For a soft deep water clay from offshore West Africa, a non-linear failure envelope has been identified through SMARTPIPE testing, with the friction angle increasing from $25^{\circ}$ to $35^{\circ}$ as the effective stress falls from $5 \mathrm{kPa}$ to $1.5 \mathrm{kPa}$ (Figure 23). This envelope is also consistent with tilt table tests (Pedersen et al. 2003) and large scale pipeline model tests (Langford et al. 2007) using the same soil.

This non-linear failure envelope can be used to assess the fully-drained axial pipe-soil resistance, but once the rate of pipe movement is sufficient for excess pore pressure to build up, the resistance generally falls. The transition from drained to undrained shearing takes place over approximately two orders of magnitude of shearing rate, and the threshold speed beyond which fully drained conditions occur can be identified through interface shear tests, or the use of novel site investigation tools that simulate pipe-soil shearing in situ at the seabed (Hill and Jacob, 2008; Yan et al., 2010).

\subsection{Numerical modelling of steel catenary risers}

A common form of connection between the seabed and a floating facility is a steel catenary riser (SCR). As its name implies, an SCR hangs as a catenary through the water column, and is subjected to motions from the floating facility, and also from currents. Critical design aspects include an ultimate limit state from excessive bending 
strains (reduced by increasing the horizontal component of tension in the SCR), and fatigue at the hang-off point and in the touchdown zone. The last aspect, fatigue in the touchdown zone, is where geotechnical considerations become important.

Fatigue is driven by cumulative cycles of stress change during the operational life of the SCR, largely due to changes in bending moment. The maximum cyclic bending moment range in the touchdown zone occurs in the region of the maximum shear force, and in turn the maximum shear force is affected by the stiffness of the seabed (Pesce et al., 1998; Randolph and White, 2008b). Although the actual riser-soil interaction is nonlinear, most dynamic modelling software used for riser design is limited to a linear spring model of the soil response. As a result, considerable attention has been focused on stiffness values for the seabed, which are typically expressed as a factor, $\mathrm{K}$, times the bearing resistance, $\mathrm{N}_{\mathrm{c}} \mathrm{S}_{\mathrm{u}}$. Typical values of $\mathrm{K}$ range from a maximum of about 200 at very small displacement amplitudes, down to below 10 for amplitudes exceeding $10 \%$ of the pipe diameter (Clukey et al., 2005, 2008).

The actual soil response may be modelled using hyperbolic functions for the reduction in stiffness with increasing displacement amplitude, and which asymptote to the bearing resistance (or uplift resistance) for large displacements (Bridge et al., 2004). Such a model, the key features of which are illustrated schematically in Figure 24, has recently been implemented in one of the main riser analysis software packages (Randolph and Quiggin, 2009). An example analysis illustrating how fatigue damage in the touchdown zone experienced over a 20-year operational period is affected by the shear strength gradient (assumed proportional to depth, $s_{u}=\rho z$ ) is shown in Figure 25. Comparisons with analyses using a linear seabed spring shows that similar fatigue damage is obtained for spring stiffnesses in the range 10 to $50 \mathrm{kPa}$ (Ting et al., 2010), which is an order of 
magnitude lower than commonly assumed in design. The non-linear riser-soil interaction model has also been used to explore the effect of trench formation on SCR fatigue in the touchdown zone (Shiri and Randolph, 2010).

\section{Submarine Slides}

The move to deeper water has increased significantly the potential risks from geohazards, particularly submarine slides - such as the Storegga slide, shown in Figure 26. Export pipelines often must negotiate unstable regions of soft seabed around the steep continental shelf and canyons with depths ranging from tens to hundreds of metres. These challenging conditions expose pipelines to the risk of a submarine slide impacting on the pipeline. Also, subsea facilities may be located within relic slides or in runout paths of potential slides. A recent well-documented example is the Mardi Gras export pipeline for the Atlantis development in the Gulf of Mexico (Jeanjean et al., 2005). This pipeline traversed the base of the Sigsbee Escarpment, which is a known area of submarine sliding (Jeanjean et al., 2005). In these environments, the risk from submarine slides is quantified via (i) an assessment of the routes of potential slides, and (ii) by an estimate of the potential loading on pipelines and infrastructure that would result from these slides.

\subsection{Modelling of slide runout}

During the runout of a submarine slide, the failed material progressively breaks down and the strength and weight properties transform accordingly, as illustrated in Figure 27. Initially, the slide is an intact block with geotechnical properties corresponding to the in-situ condition. The block then transitions into a debris flow, with the soil deforming and weakening. As the debris flow advances, further degradation of the material takes 
place and water becomes entrained in the soil, leading to operative strengths - or mobilised fluid shear stresses - as low as $0.1 \mathrm{kPa}$. Laboratory testing has shown that the strength of soil decays steadily with increasing moisture content across the fluid-solid boundary. The Herschel-Bulkley form of rheology can capture the variation in ratedependent shear strength of soils across the range of moisture content that spans from solid to fluid (Boukpeti et al., 2009, 2010; Jeong et al., 2009). This allows a consistent treatment of the material response throughout all stages of the run-out process, rather than requiring a solid to liquid phase transformation to be invoked.

Experimental modelling of the run-out behaviour of submarine slides in fine grained soils has thus far been limited to large scale flume experiments (Mohrig et al., 1998; Marr et al., 2001; Mohrig and Marr, 2003; Ilstad et al., 2004; Toniolo et al., 2004). These experiments have examined the frontal dynamics of submarine slides, the initiation of hydroplaning and the transition from debris flow to turbidity current. In all cases the experiments began with a fully fluidised slide mass that was poured into the flume. It had a strength substantially lower (typically $\tau_{\text {yield }} \sim 0.1 \mathrm{kPa}$ ) - by two orders of magnitude - than typical intact slide material, so did not replicate the gradual softening and strength reduction that occurs during the initial stages of runout. Centrifuge modelling of submarine slide triggering mechanisms has been undertaken (Coulter and Phillips 2003) and Boylan et al. (2010) describe a facility to model runout behaviour, starting with intact soil, using the long internal channel of the drum centrifuge at UWA. A consolidated slide block is released, to run out along a model seabed in the drum channel. Initial tests show that the run-out length is controlled by the superposed effects of both significant water entrainment during the run-out process and softening of the material, as shear strain accumulates. 
Numerical modelling of the runout of potential slides often follows a fluid mechanics approach where the rheology of the debris material is described using either a linear viscoplastic Bingham model or a non-linear viscoplastic Herschel-Bulkley model. The runout process is commonly modelled using finite difference flow models based on depth integrated equations of mass and momentum conservation, solved within a Lagrangian framework. Imran et al. (2001) developed a program, called BING, that models the 1-D spreading of a debris flow down slope, while Niedoroda et al. (2006) developed the DM-2D program which models two dimensional (2-D) spreading. A weakness of these programs is that, except for changes in the shear strength of the slide mass due to viscous effects, the shear strength remains constant during runout, which ignores any strength degradation or water entrainment processes.

To model the runout of potential slides, designers often assume that the initial strength of the slide mass is equal to the fully remoulded strength or a value derived from hindcasts of historical failures. However, the strength values required to match the runout of historical failures are often an order of magnitude lower than the local remoulded strength. De Blasio et al. (2004) and Elverhøi et al. (2005) described various extensions to the BING program to tackle this discrepancy, taking account of hydroplaning (potentially occurring at the slide-seabed interface), hydrodynamic drag, the inclusion of large blocks of intact material and a method to account for a process of softening, referred to as 'shear wetting'. Boylan and White (2010) developed a program, entitled UWA-SM${ }^{3}$, that models slide run-out using a Herschel-Bulkley rheology and depth averaged mass and momentum continuity. Strength degradation during runout is accounted for, with the degradation parameters being obtained from cyclic full flow penetrometer tests. Figure 28 shows an example of the run-out of a slide block on a 
uniform slope with $5^{\circ}$ inclination, modelled using UWA-SM${ }^{3}$. In this case, inclusion of softening increased the run-out by a factor of 2.4. Note that the predicted shape of the runout is relatively uniform, contrasting with the (often) irregular thickness observed in actual submarine slides. This partly reflects limitations in the depth-averaged computational approach, which tends to restrict the formation of outrunner blocks that may become detached due to local softening on a plane either beneath or within the slide body. The formation of outrunners is also a function of the seabed topography over which the runout occurs, which was assumed flat in this example.

More sophisticated numerical techniques that avoid the use of depth-averaged conditions provide an alternative, albeit computationally more demanding, approach to slide simulation. Gauer et al. (2005) used a computation fluid dynamics (CFD) model with strain softening to replicate the retrogressive failures evident in the seismic profiles near the head of the Storegga slide. Wang et al. (2010b) described a method based on the ABAQUS continuum finite element analysis software that allows the extremely large deformations and long run-out distances of a submarine slide to be accommodated. Using this approach, outrunner blocks are observed to form for certain combinations of slide geometry and soil parameters, which is an aspect of slide behaviour that is difficult to replicate using depth-averaged methods. Although the continuum methods have overcome the computational difficulties with modelling long run-out processes, there is no established approach to accommodate the process of water entrainment within the rheological models used for the slide material. 


\subsection{Assessment of loading on infrastructure}

To assess the impact of slide loading on pipelines or other infrastructure, the loading is traditionally assessed using either a geotechnical approach where the force on the pipeline is linked to the soil strength using a bearing factor $\left(\mathrm{N}_{\mathrm{p}}\right)$ or a fluid dynamics approach that evaluates drag forces on the pipeline, so the loading depends on the velocity and density of the flow (Bruschi et al., 2006; Parker et al., 2008). The two approaches represent the two extremes during submarine slide runout . The geotechnical approach better represents the early stages of runout, when the strength is close to the intact in-situ value and the velocity is low. At the other extreme, the fluid mechanics approach is most applicable to a turbidity current when the flowing material is a heavy fluid. In reality, the loading on the pipe arises both from the strength of the deforming soil and its inertia. Also, the strength of a soil decreases continuously with increasing moisture content across the boundary that conventionally delineates solid and fluid behaviour (Boukpeti et al., 2009, 2010). Emerging analysis methods that are applicable across the solid-fluid transition use superposition to capture both effects. For the case of loading normal to a pipeline, the load per unit length $\left(F_{n}\right)$ of a pipeline of diameter, $D$ can be calculated by:

$$
F_{n}=C_{d}\left(\frac{1}{2} \rho V^{2}\right) D+N_{p} s_{u-o p} D
$$

where $C_{d}$ is a drag coefficient representing the inertia-based resistance, $\rho$ is the mass density, $\mathrm{V}$ is the velocity and $\mathrm{s}_{\mathrm{u}-\mathrm{op}}$ is the operative undrained shear strength. The operative shear strength should be chosen, noting the operative strain rate and its influence on the shear strength, the degree of softening and the possible entrainment of water in the soil. Recent research (e.g. Zakeri et al., 2008; Zhu and Randolph, 2010) has 
used a combination of model testing and numerical analysis to establish the relevant drag and bearing factors, and to test the applicability of superposition following Equation (4).

\section{Conclusions}

This paper has reviewed a range of geotechnical design issues associated with oil and gas developments in deep water. These range from new in situ techniques to characterise seabed sediments, to shallow foundations subjected to multi-dimensional loading, anchoring systems, pipelines and risers, and finally submarine slides and their potential impact on infrastructure. Recent developments in each of these areas are highlighted, with particular emphasis on the roles played by sophisticated centrifugebased physical modelling and numerical analysis adapted to simulate large deformations.

As the offshore industry continues to move towards deeper waters and harsher environments, new foundation technologies will arise in the near future, providing new geotechnical challenges with increasing reliance on in situ test data to determine key design parameters. Among the current and anticipated research issues, the most noteworthy include issues associated with moving boundaries. As discussed in the paper, applications such as dynamic anchors and submarine pipelines involve large displacements at rates potentially varying a few orders of magnitude. New design methodologies are required to account for large deformations, strain rate softening or hardening, varying degrees of drainage coupled with episodes of consolidation, potential soil-fluid-structure interaction and unusual near-surface behaviour. The low effective stress level relevant for pipeline and riser design brings additional challenges 
in terms of our understanding, and the capabilities of conventional laboratory testing apparatus. Thoughtful extensions of critical state soil mechanics, focusing on material behaviour at the micro-level, are needed to address the effects of sequential episodes of softening under cyclic loading followed by reconsolidation.

Improved assessment of geotechnical risks is also needed in response to community demands and government regulations. Better integration in design of the natural variability of soil properties and environmental loading, requires stochastic methods and risk based prediction methods to replace traditional deterministic design methods.

The increasing sophistication of offshore geotechnical structures implies an equivalent increasing sophistication in modelling techniques. Physical modelling and numerical modelling techniques are starting to merge into hybrid modelling techniques where geotechnical physical model tests are controlled in real time by output from numerical modelling, and vice versa. These new techniques, already under development in the earthquake modelling community, will allow more realistic simulations, accounting for soil-fluid-structure interaction and potentially complex coupling of mechanical, hydraulic and thermal effects.

\section{Acknowledgements}

The work forms part of the activities of the Centre for Offshore Foundation System at UWA, which was established under the Australian Research Council's Special Research Centre scheme and is now supported by the State Government of Western Australia through the Centre of Excellence in Science and Innovation program. The authors acknowledge extensive support through the ARC's Federation and Future Fellowships, Discovery and Linkage programs, and the CSIRO Flagship Collaboration Fund. 


\section{REFERENCES}

Acosta-Martínez, H.E., Gourvenec, S.M., Randolph, M.F., 2010. Some design recommendations for skirted shallow foundations. Proc $2^{\text {nd }}$ Int. Symp. on Frontiers in Offshore Geotechnics (ISFOG), Perth.

Andersen, K.H., Jostad, H.P., 2002. Shear strength along outside wall of suction anchors in clay after installation. Proc. Int. Symp. Offshore and Polar Engng. Conf. (ISOPE), Kitakyushu, Japan, 785-794.

Andersen, K.H., Jostad, H.P., 2004. Shear strength along inside of suction anchor skirt wall in clay. Proc. Offshore Tech. Conf., Houston, Paper OTC 16844.

Andersen, K.H., Murff, J.D., Rabdolph, M.F., Clukey, E.C., Erbirch, C.T., Jostad, H.P., Hansen, B., Aubeny, C., Sharma, P., Supachawarote, C., 2005. Suction anchors for deep water applications. Proc. Int. Symp. Frontiers in Offshore Geotechnics (ISFOG), Perth, 3-32.

Andersen, K.H.A., Lunne, T., Kvalstad, T., Forsberg, C.F., 2008. Deep water geotechnical engineering. Proc. XXIV Nat. Conf. of the Mexican Soc. of Soil Mechanics, Aguascalientes, 1-57.

API RP 2A 21st Edition, 2000. Recommended Practice for Planning, Designing and Constructing Fixed Offshore Platforms - Working Stresses Design. American Petroleum Institute, Washington.

Audibert, J.M.E., Movant, M. N., Won, J.Y., Gilbert, R.B., 2006. Torpedo piles: laboratory and field research. Proc. 16th Int. Offshore and Polar Eng. Conf., San Francisco, 462-468.

Bienen, B., Byrne, B.W., Houlsby, G.T., Cassidy, M.J., 2006. Investigating six-degree-of-freedom loading of shallow foundations on sand. Géotechnique 56 (6), 367-379.

Bienen, B., Gaudin, C., Cassidy, M.J., 2007. Centrifuge tests of shallow footing behaviour on sand under combined vertical torsional loading. Int. J. of Physical Modelling in Geotechnics, 7 (2), 1-22.

Borel, D., Puech, A., Dendani, H., Colliat, J-L., 2005. Deep water geotechnical site investigation practice in the Gulf of Guinea. Proc. Int. Symp. on Frontiers in Offshore Geotechnics (ISFOG), Perth, 921-926.

Borel, D., Puech, A., Dendani, H., de Ruijter, M., 2002. High quality sampling for deep water geotechnical engineering: the STACOR ${ }^{\circledR}$ Experience. Proc. Symp on Ultra Deep Engineering and Technology, Brest, France.

Boukpeti, N., White, D.J., Randolph, M.F. 2009. Characterization of the solid-liquid transition of finegrained sediments. Proc. Conf. on Offshore Mechanics and Arctic Engineering, ASME, Honolulu, Paper OMAE2009-79738.

Boukpeti, N., White, D.J., Randolph, M.F., Low, H.E. 2010. The strength of fine-grained soils at the solid-fluid transition Géotechnique, submitted May 2009, in review.

Boylan, N., Gaudin, C., White, D. J., Randolph, M. F., 2010. Centrifuge modelling of submarine slides. Submitted to Ocean Engineering.

Boylan, N., Long, M., Ward, D., Barwise, A., Georgious, B., 2007. Full flow penetrometer testing in Bothkennar Clay. Proc. 6th Int. Conf. on Offshore Site Investigation and Geotechnics, Society for Underwater Technology, London, 177-186.

Boylan, N., White, D. J., 2010. Depth-averaged numerical modelling of submarine slide run-out in softening soil. Submitted to Canadian Geotechnical Journal.

Bransby, M.F., Randolph, M.F. 1998. Combined loading of skirted foundations. Géotechnique 48 (5), 637-655.

Bridge, C., Laver, K., Clukey, E., Evans, T., 2004. Steel catenary riser touchdown point vertical interaction models. Proc. Offshore Technology Conf., Houston, Paper OTC 16628.

Bruschi, R., Bughi S., Spinazzè M., Torselletti E., Vitali L., 2006. Impact of debris flows and turbidity currents on seafloor structures. Norwegian Journal of Geology, 86, 317-337.

Bruton, D.A.S., Carr, M.C., White D J., 2007. The influence of pipe-soil interaction on lateral buckling and walking of pipelines: the SAFEBUCK JIP. Proc. Int. Conf. on Offshore Site Investigation and Geotechnics, Soc. Underwater Tech. London, 133-150.

Bruton, D., White D.J., Langford, T.L., Hill, A. 2009. Techniques for the assessment of pipe-soil interaction forces for future deepwater developments Proc. Offshore Tech. Conf., Houston, Paper OTC 20096.

Byrne, B.W., Houlsby, G.T., 2005. Investigating 6 degree of freedom loading on shallow foundations, Proc Int. Symp. on Frontiers in Offshore Geotechnics (ISFOG), Perth, 477-482.

Carr, M., Sinclair, F., Bruton, D., 2006. Pipeline walking — understanding the field layout challenges, and analytical solutions developed for the SAFEBUCK JIP. Proc. Offshore Tech. Conf., Houston, Paper OTC 17945.

Cassidy, M.J., Cheong, J., 2005. The behaviour of circular footings on sand subjected to combined vertical-torsion loading. Int. Journal of Physical Modelling in Geotechnics, 5 (4), 1-14.

Chen, W., Randolph, M.F., 2007a. Axial capacity and stress changes around suction caissons. Géotechnique 57 (6), 499-511.

Chen, W., Randolph, M.F., 2007b. Uplift capacity of suction caissons under sustained and cyclic loading in soft clay. J. Geotech. and Geoenv. Engng, ASCE, 133 (11), 1352-1363. 
Chen, W., Zhou, H., Randolph, M.F., 2009. Effect of installation methods on external shaft friction of caissons in soft clay. J. Geotech. and Geoenv. Engng, ASCE, 135(5), 605-615.

Clukey, E.C., Haustermans, L., Dyvik, R., 2005. Model tests to simulate riser-soil interaction effects in touchdown point region. Proc. Int. Symp. on Frontiers in Offshore Geotechnics (ISFOG), Perth, 651658.

Clukey, E.C., Phillips, R., 2002), Centrifuge model tests to verify suction caisson capacities for taut and semi-taut legged mooring systems. Deep Offshore Technology Int. Conf., New Orleans.

Clukey, E.C., Templeton, J.S., Randolph, M.F., Phillips, R.A., 2004. Suction caisson response under sustained loop-current loads. Proc. Offshore Tech. Conf., Houston, Paper OTC 16843.

Clukey, E.C., Young, A.G., Dobias, J.R., Garmon, G.R., 2008. Soil response and stiffness laboratory measurements of SCR pipe/soil interaction. Proc. Offshore Technology Conf., Houston, Paper OTC 19303.

Coulter, S. E., Phillips, R., 2003. Simulating submarine slope instability initiation using centrifuge model testing. Proc. of 1st Int. Symp. on Submarine Mass Movements and Their Consequences. Nice, France. Kluwer Academic, 29-36.

de Aguiar, C. S., de Sousa, J. R. M., Ellwanger, G. B.,Porto, E. C., de Medeiros Júnior, C. J., Foppa, D., 2009. Undrained load capacity of torpedo anchors in cohesive soils. Proc. 28th Int. Conf. Ocean, Offshore and Arctic Eng., OMAE 2009, ASME, Honolulu, OMAE2009-79465.

De Blasio, F.V., Elverhoi, A., Issler, D., Harbitz, C.B., Bryn, P., Lien, R., 2004. Flow models of natural debris flows originating from overconsolidated clay materials. Marine Geology 213, 439-455.

DeJong, J., Yafrate, N., DeGroot, D., Low, H.E., Randolph, M.F., 2010. Recommended practice for full flow penetrometer testing and analysis. ASTM, 33 (2), DOI: 10.1520/GTJ102468.

DeJong, J.T., Yafrate, N.J., Randolph, M.F., 2008. Use of pore pressure measurements in a ball full-flow penetrometer. Proc. 3rd Int. Conf. on Site Characterization, Taipei, 1269-1275.

Dingle, H.R.C., White, D.J., Gaudin, C., 2008. Mechanisms of pipe embedment and lateral breakout on soft clay. Canadian Geotech. J. 45 (5), 636-652.

DNV, 1992. Foundations: Classification notes No. 30.4, Det Norske Veritas, Oslo.

Dove, P., Treu, H., Wilde, B., 1998. Suction embedded plate anchor (SEPLA): a new anchoring solution for ultra-deep water mooring. Proc. Deep Offshore Tech. Conf., New Orleans.

Einav, I., Randolph, M.F., 2005. Combining upper bound and strain path methods for evaluating penetration resistance. Int. J. Numerical Methods in Engineering, 63 (14), 1991-2016.

Elverhøi, A., Issler, D., De Blasio, F. V., Ilstad, T., Harbitz, C., Gauer, P., 2005. Emerging insights into the dynamics of submarine debris flows. Natural Hazards and Earth System Sciences, 5, 633-648.

Finnie, I.M.S., Morgan, N 2004, 'Torsional loading of subsea structures', Proceedings of The Fourteenth International Offshore and Polar Engineering Conference, Toulon, 326-333.

Gaudin, C., Cassidy, M.J., Bienen, B., Hossain, M.S., 2010a. A review of the recent contribution made by geotechnical centrifuge modelling to the understanding of jack-up spudcan behaviour. Ocean Engineering, Submitted for review in this special issue on 7 June 2010.

Gaudin, C., Clukey, E.C., Garnier, J., Phillips, R., 2010b. New frontiers for centrifuge modelling in offshore geotechnics. Proc. $2^{\text {nd }}$ Int. Symp. on Frontiers in Offshore Geotechnics, Perth.

Gaudin, C., O’Loughlin, C.D., Randolph, M.F., Lowmass, A.C., 2006. Influence of the installation process on the behaviour of suction embedded plate anchors. Géotechnique, 56 (6), 381-391.

Gaudin, C., Simkin, M., White, D.J., O’Loughlin, C.D., 2010c. Experimental investigation into the influence of a keying flap on the keying behaviour of plate anchors. Proc. 20th Int. Offshore and Polar Eng. Conf., Beijing, China.

Gaudin, C., Tham, K.H., Ouahsine, S., 2008. Plate anchor failure mechanism during keying process. Proc. 18th Int. Offshore and Polar Eng. Conf., Vancouver, Canada, 2, 613-620.

Gauer, P., De Blasio, F.V., Elverhøi, A., 2007. An international perspective I or II: Dynamic modeling of submarine slide run-out/submarine mass movements; where do we stand and what are the main challenges. Proc. Offshore Tech. Conf., Houston, Paper OTC 18597.

Gourvenec, S.M., 2007a. Shape effects on the capacity of rectangular footings under general loading. Géotechnique, 57 (8), 637-646.

Gourvenec, S.M., 2007b. Failure envelopes for offshore shallow foundation under general loading. Géotechnique, 57 (9), 715-727.

Gourvenec, S.M., Acosta-Martinez, H.E., Randolph, M.F., 2009. Experimental study of uplift resistance of shallow skirted foundations in clay under concentric transient and sustained loading. Géotechnique, 59 (6), 525-537.

Gourvenec, S.M., Randolph, M.F., 2003. Effect of strength non-homogeneity on the shape and failure envelopes for combined loading of strip and circular foundations on clay. Géotechnique, 53 (6), 575586. 
Gourvenec, S.M., Randolph, M.F., 2009. Effect of foundation embedment and soil properties on consolidation response, Proc. Int. Conf. Soil. Mech. and Geotech. Engng (ICSMGE), Alexandria, Egypt, 638-641.

Gourvenec, S.M., Randolph, M.F., 2010. Consolidation beneath skirted foundations due to sustained loading. Int. J. of Geomechanics, ASCE, 10 (1), 22-29.

Gourvenec, S.M., White, D.J., 2010. Elastic solutions for consolidation around seabed pipelines. Proc. Annual Offshore Tech. Conf., Houston. Paper OTC 20554.

Hill, A.J., Jacob, H., 2008. In-situ measurement of pipe-soil interaction in deep water. Proc. Offshore Tech. Conf., Houston. Paper OTC 19528.

Ilstad, T., De Blasio, F. V., Elverhøi, A., Harbitz, C. B., Engvik, L. E., Longva, O., Marr, J. G., 2004. On the frontal dynamics and morphology of submarine debris flows. Marine Geology, 213, 481-497.

Imran, J., Harff, P., Parker, G., 2001. A numerical model of submarine debris flow with graphical user interface. Computers and Geosciences, 27, 717-729.

ISO, 2003. ISO 19901-4:2003(E): Petroleum and Natural Gas Industries - Specific Requirements for Offshore Structures, Part 4: Geotechnical and Foundation Design. ISO, Geneva.

Jayson, D., Delaporte, P., Alber,t J.-P., Prevost, M.E., Bruton, D., Sinclair, F., 2008. Greater Plutonio project - subsea flowline design and performance. Proc. Conf. on Offshore Pipeline Technology, OPT. Amsterdam

Jeanjean, P., 2006. Set-up characteristics of suction anchors for soft Gulf of Mexico clays: Experience from field installation and retrieval. Proc. Offshore Tech. Conf., Houston, Paper OTC 18005.

Jeanjean, P., Liedtke, E., Clukey, E. C., Hampson, K., Evans, T., 2005. An operator's perspective on offshore risk assessment and geotechnical design in geohazard-prone areas. Proc. Int. Symp. on Frontiers in Offshore Geotechnics (ISFOG), Perth, 115-143.

Jeanjean, P., Watson, P.G., Kolk, H.J., Lacasse, S., 2010. RP 2Geo: The new API recommended practice for geotechnical engineering. Proc. Offshore Tech. Conf., Houston, Paper OTC 20631.

Jeanjean, P., Znidarcic, D., Phillips, R., Ko, H. Y., Pfister, S., Schroeder, K., 2006. Centrifuge testing on suction anchors: Double wall, stiff clays, and layered soil profile. Proc., Offshore Tech. Conf., Houston, Paper OTC 18007.

Jeong, S.W., Lerouil, S., Locat, J., 2009. Applicability of power law for describing rheology of soils of different origins and characteristics. Canadian Geot. J., 46, 1011-1023.

Kelleher, P.J., Randolph, M.F., 2005. Seabed geotechnical characterisation with the portable remotely operated drill. Proc. Int. Symp. on Frontiers in Offshore Geotechnics (ISFOG), Perth, 365-371.

Krost, K., Gourvenec, S.M., White, D., 2010. Consolidation around partially embedded submarine pipelines. Géotechnique, published ahead of print 10.1680/geot.8.T.015.

Langford, T.E., Dyvik, R., Cleave, R., 2007. Offshore pipeline and riser geotechnical model testing: practice and interpretation. Proc. Conf. on Offshore Mech. and Arctic Engng - OMAE, ASME San Diego, Paper OMAE2007-29458.

Lieng, J.T., Hove, F., Tjelta, T.I., 1999. Deep Penetrating Anchor: Subseabed deep water anchor concept for floaters and other Installations. Proc. 9th Int. Offshore and Polar Eng. Conf., ISOPE, Brest, 613619.

Lieng, J.T., Tjelta, T.I., Skaugset, K., 2010. Installation of two prototype deep penetrating anchors at the Gjøa field in the North Sea. Proc. Offshore Tech. Conf., Houston, Paper OTC 20758.

Low, H.E., Lunne, T., Andersen, K.H., Sjursen, M.A., Li, X., Randolph, M.F., 2010. Estimation of intact and remoulded undrained shear strength from penetration tests in soft clays. Géotechnique, in press.

Low, H..E., Randolph, M.F., Kelleher, P., 2007. Estimation of in-situ coefficient of consolidation from dissipation tests with different penetrometers. Proc. 6th Int. Conf. Offshore Site Investigation and Geotechnics, Society for Underwater Technology, London, 547-556.

Low, H.E., Randolph, M.F., Rutherford, C.J., Bernard, B.B., Brooks, J.M., 2008. Characterization of near seabed surface sediment. Proc. Offshore Tech. Conf., Houston, Paper OTC 19149.

Lunne, T., Andersen, K.H., Low, H.E., Sjursen, M., Li, X., Randolph, M.F., 2010. Guidelines for offshore in situ testing and interpretation in deep water soft soils, Canadian Geotechnical J. (provisionally accepted).

Marr, J. G., Harff, P. A., Shanmugam, G., Parker, G., 2001. Experiments on subaqueous sandy gravity flows: The role of clay and water content in flow dynamics and depositional structures. GSA Bulletin, 113, 1377-1386.

Martin, C.M., Randolph, M.F., 2006. Upper bound analysis of lateral pile capacity in cohesive soil. Géotechnique, 56 (2), 141-145.

Medeiros, C. J., 2001. Torpedo anchor for deep water. Proc. Deep water Offshore Technology Conf., Rio de Janeiro.

Medeiros, C.J., 2002. Low cost anchor system for flexible risers in deep waters. Proc. Offshore Tech. Conf., Houston, Paper OTC 14151. 
Merifield, R.S., White, D.J., Randolph, M.F., 2008. The ultimate undrained resistance of partiallyembedded pipelines. Géotechnique 58 (6), 461-470.

Mohrig, D., Marr, J. G., 2003. Constraining the efficiency of turbidity current generation from submarine debris flows and slides using laboratory experiments. Marine and Petroleum Geology, 20, 883-889.

Mohrig, D., Whipple, K.X., Hondzo, M., Ellis, C., Parker, G., 1998. Hydroplaning of subaqueous debris flows. GSA Bulletin, 110 (3), 387-394.

Murff, J.D., Aubeny, C.P., Yang, M., 2010. The effect of torsion on the sliding resistance of rectangular foundations. Proc 2nd Int. Symp. on Frontiers in Offshore Geotechnics (ISFOG), Perth.

Murff, J.D., Miller, T.W., 1977. Stability of offshore gravity structure foundations using the upper bound method. Proc. Offshore Tech. Conf., Houston, Paper OTC 2896.

Newlin, J.A., 2003. Suction anchor piles for the Na Kika FDS mooring system, Part 1: site characterization and design. Deepwater Mooring Systems: Concepts, Design, Analysis, and Materials, ASCE, Houston, USA, 28-54.

Niedoroda, A.W., Reed, C. W., Das, H.S., Hatchett, J.L., Perlet, A.B., 2006. Controls of the behavior of marine debris flows. Norwegian Journal of Geology, 86 (4), 265-274.

O’Loughlin, C.D., Lowmass, A., Gaudin, C.D. \& Randolph, M. F., 2006. Physical modelling to assess keying characteristics of plate anchors, Proc. Int. Conf. on Physical Modelling in Geotechnics, Hong Kong, 1, 659-665.

O’Loughlin, C.D, Randolph, M.F., Richardson, M., 2004. Experimental and theoretical studies of deep penetrating anchors. Proc. Offshore Tech. Conf., Houston, Paper OTC 16841.

O’Loughlin, C.D., Richardson, M.D., Randolph, M.F., 2009. Centrifuge tests on dynamically installed anchors, Proc. 28th Int. Conf. on Offshore Mech. and Arctic Eng., OMAE, ASME, Honolulu, Paper OMAE2009-80238.

Parker, E.J., Evans, T., 2008. Evaluation of landslide impact on deep water submarine pipelines. Proc. Offshore Tech. Conf., Houston, Paper OTC 19459.

Pedersen, R.C., Olsen, R.E., Rausch, A.F., 2003. Shear and interface strength of clay at very low effective stresses. ASTM Geotechnical Testing J. 26 (1), 71-783.

Pesce, C. P., Aranha, J. A. P., Martins, C. A., 1998. The soil rigidity effect in the touchdown boundary layer of a catenary riser: static problem. Proc. 8th Int. Offshore and Polar Engineering Conf. - ISOPE, Montreal, Canada, 207-213.

Puech, A., Orozco-Calderon, M., Foray, P., 2010. Mini T-bar testing at shallow penetration. Proc. 2nd Int. Symp. on Frontiers in Offshore Geotechnics, ISFOG, Perth.

Randolph, M.F., 2004. Characterisation of soft sediments for offshore applications, Keynote Lecture, Proc. 2nd Int. Conf. on Site Characterisation, Porto, 1, 209-231.

Randolph, M.F., Cassidy, M.J., Gourvenec, S.M., Erbrich, C., 2005. Challenges of offshore geotechnical engineering. Proc. 16th Int. Conf. Soil Mech. and Geotech. Eng., Osaka, Japan, 1, 123-176.

Randolph, M.F., Gourvenec, S.M., 2010. Offshore Geotechnical Engineering, Taylor \& Francis, London, ISBN 978-0-415-47744-4.

Randolph, M.F., Houlsby, G.T., 1984. The limiting pressure on a circular pile loaded laterally in cohesive soil. Géotechnique, 34 (4), 613-623.

Randolph, M.F., House, A.R., 2002. Analysis of suction caisson capacity in clay. Proc. Offshore Tech. Conf., Houston, Paper OTC 14236

Randolph M.F., Low, H.E., Zhou, H., 2007. In situ testing for design of pipeline and anchoring systems. Keynote paper, Proc. 6th Int. Conf. Offshore Site Investigation and Geotechnics, Society for Underwater Technology, London, 251-262.

Randolph, M.F., Martin, C.M., Hu, Y., 2000. Limiting resistance of a spherical penetrometer in cohesive material. Géotechnique, 50 (5), 573-582.

Randolph, M.F., Quiggin, P., 2009. Non-linear hysteretic seabed model for catenary pipeline contact, Proc. 28th Int. Conf. on Offshore Mech. and Arctic Eng., OMAE, ASME, Honolulu, Paper OMAE2009-79259.

Randolph, M.F., Wang, D., Zhou, H., Hossain, M.S., Hu, Y., 2008. Large deformation finite element analysis for offshore applications. Keynote paper, Proc. 12th Int. Conf. of Int. Assoc. for Comp. Methods and Advances in Geomechanics, IACMAG-08, Goa, India, 3307-3318.

Randolph, M.F., White, D.J., 2008a. Upper bound yield envelopes for pipelines at shallow embedment in clay. Géotechnique 58 (4), 297-301.

Randolph, M.F., White, D.J., 2008b. Pipeline embedment in deep water: processes and quantitative assessment. Proc. Offshore Tech. Conf., Houston, Paper OTC 19128.

Richardson, M.D., O’Loughlin, C.D., Randolph, M.F., 2005. The geotechnical performance of deep penetrating anchors in calcareous sand. Proc. Int. Symp. on Frontiers in Offshore Geotechnics (ISFOG), Perth, 357-363. 
Richardson, M.D., O’Loughlin, C.D., Randolph, M.F., Cunningham, T.J., 2006. Drum centrifuge modelling of dynamically penetrating anchors. Proc. 6th Int. Conf. on Physical Modelling in Geotechnics, Hong Kong, 1, 673-678.

Richardson, M.D., O’Loughlin, C.D., Randolph, M.F., Gaudin, C., 2009. Setup following installation of dynamic anchors in normally consolidated clay. J. of Geotech. and GeoEnvironmental Eng., ASCE, 135 (4), 487-496.

Rigzone, 2006. Permanent SEPLA Mooring Unit Installed in Gulf. Rigzone Magazine, www. rigzone.com/news/article.asp?a_id=30962. April 4, 2006.

Sagrilo, L.V.S., de Sousa, J.R.M., de Lima, E.C.P., Porto, E.C., Fernandes, J.V.V., Foppa, D., 2010. Reliability based design of torpedo anchor. Proc. 29th Int. Conf. Ocean, Offshore and Arctic Eng., OMAE, ASME, Shanghai, China, OMAE2010-21082.

Senpere, D., Auvergne, G.A., 1982. Suction anchor piles - a proven alternative to driving or drilling. Proc. Offshore Tech. Conf., Houston, Paper OTC 4206.

Shelton, J.T., 2007. OMNI-Max anchor development and technology. Proc. Ocean Conf., Vancouver, Canada.

Shiri, H., Randolph, M.F., 2010. The influence of seabed response on fatigue performance of steel catenary risers in touchdown zone. Proc. 29th Int. Conf. on Ocean, Offshore and Arctic Engineering, OMAE, ASME, Shanghai, Paper OMAE2010-21153.

Song, Z., Hu, Y, O’Loughlin, C.D., Randolph, M.F., 2009. Loss in anchor embedment during plate anchor keying in clay. J. of Geot. and Geoenv. Eng., ASCE, 135 (10), 1475-1485.

Song, Z., Hu, Y., Randolph, M.F., 2008. Numerical simulation of vertical pullout of plate anchors in clay. J. of Geotech. and Geoenvironmental Eng., ASCE, 134 (6), 866-875.

St $\phi v e$, O.J., Bysveen, S., Christophersen, H.P., 1992. New foundation systems for the Snorre development. Proc. Offshore Tech. Conf., Houston, Paper OTC 6882.

Taiebat, H.A., Carter, J.P., 2000. Numerical studies of the bearing capacity of shallow foundations on cohesive soil subjected to combined loading. Géotechnique, 50 (4), 409-418.

Taiebat, H.A., Carter, J.P., 2010. A failure surface for circular footings on cohesive soils. Géotechnique, 60 (4), 265-273.

Ting, I., Kimiaei, M., Randolph, M.F., 2010. Advanced nonlinear hysteretic seabed model for dynamic fatigue analysis of steel catenary risers. Proc. 2nd Int. Symp. on Frontiers in Offshore Geotechnics, ISFOG, Perth.

Toniolo, H., Harff, P., Marr, J.G., Paola, C., Parker, G., 2004. Experiments on reworking by successive unconfined subaqueous and subaerial muddy debris flows. J. of Hydraulic Engineering, ASCE 130 (1), 38-48.

Tørnes, K., Jury, J., Ose, B. 2000. Axial creeping of high temperature flowlines caused by soil racheting. Proc. Conf. on Offshore Mechanics and Arctic Engineering, ASME, OMAEPIPE5055

Ukritchon, B. Whittle, A.J., Sloan, S.W. 1998. Undrained limit analysis for combined loading of strip footings on clay. J. Geot. and Geoenv. Eng., ASCE 124 (3), 265-276.

Wang, D, Hu, Y., Randolph, M.F., 2010a. Keying of rectangular plate anchors in normally consolidated clays. J. of Geotech. and Geoenvironmental Eng., ASCE, (revised May 2010).

Wang, D., Randolph, M.F., White, D.J., 2010b. A dynamic large deformation finite element method and element addition technique. Int. J. of Geomechanics, ASCE, in review.

White D.J., Cathie D.N., 2010a. Geotechnics for subsea pipelines. Proc. 2nd Int. Symp. on Frontiers in Offshore Geotechnics, ISFOG. Perth.

White, D.J., Hill, A.J., Westgate, Z., Ballard, J-C, 2010. Observations of pipe-soil response from the first deep water deployment of the SMARTPIPE. Proc. 2nd Int. Symp. on Frontiers in Offshore Geotechnics, ISFOG. Perth.

White, D.J., Hodder, M., 2010. A simple model for the effect on soil strength of episodes of remoulding and reconsolidation. Canadian Geotechnical Journal 47(7), 821-826.

White D.J., Take W.A., Bolton M.D., 2003. Soil deformation measurement using Particle Image Velocimetry (PIV) and photogrammetry. Géotechnique 53 (7):619-631

Wilde, B., Treu, H., Fulton, T., 2001. Field testing of Suction Embedded Plate Anchors. Proc. 11th Int. Offshore and Polar Eng. Conf., 544-551.

Yafrate, N., DeJong, J., DeGroot, D., Randolph, M.F., 2009. Evaluation of remolded shear strength and sensitivity of soft clay using full flow penetrometers. Journal of Geotechnical and Geoenvironmental Engineering, ASCE, 135 (9), 1179-1189.

Yan, Y., White, D.J., Randolph, M.F., 2010. Investigations into novel shallow penetrometers for finegrained soils. Proc. 2nd Int. Symp. on Frontiers in Offshore Geotechnics, ISFOG, Perth

Young, A.G., Honganen, C.D., Silva, A.J., Bryant, W.R., 2000. Comparison of geotechnical properties from large diameter long cores and borings in deep water Gulf of Mexico. Proc. Offshore Tech. Conf., Houston, Paper OTC 12089. 
Yun, GJ, Maconochie, A, Oliphant, J, Bransby, M.F, 2009. Undrained capacity of surface footings subjected to combined V-H-T loading. Proc. 19th Int. Offshore and Polar Engineering Conf., Osaka, Japan.

Zakeri, A., Høeg, K., Nadim, F., 2008. Submarine debris flow impact on pipelines - Part I: Experimental investigation. Coastal Engineering, 55 (12), 1209-1218.

Zhou, H., Randolph, M.F., 2009a. Resistance of full-flow penetrometers in rate-dependent and strainsoftening clay. Géotechnique, 59 (2), 79-86.

Zhou, H., Randolph, M.F., 2009b. Numerical investigations into cycling of full-flow penetrometers in soft clay. Géotechnique, 59 (10), 801-812.

Zhou, H., White, D.J., Randolph, M.F., 2008. Physical and numerical simulation of shallow penetration of a cylindrical object in soft clay. Proc. GeoCongress 2008, Characterization, Monitoring and Modeling of GeoSystems, New Orleans, ASCE Geotechnical Special Publication No. 179, 108-117.

Zimmerman, E.H., Smith, M.W., Shelton J.T., 2009.Efficient gravity installed anchor for deep water mooring. Proc. Offshore Tech. Conf., Houston, Paper OTC 20117.

Zhu, H., Randolph, M.F., 2010. Numerical analysis of a cylinder moving through rate-dependent soils. Ocean Engineering (under review). 


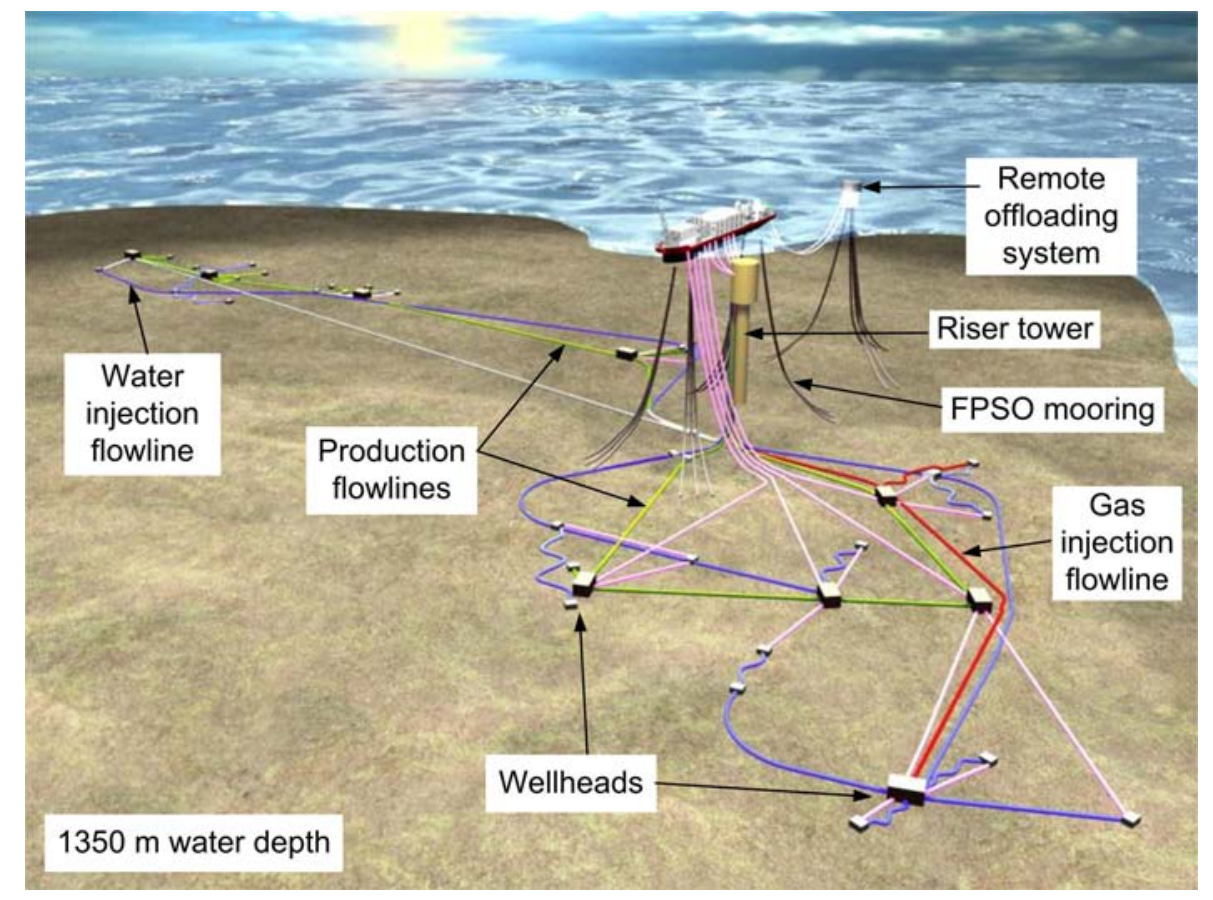

Figure 1 Example in-field layout - Greater Plutonio Project, offshore

Angola (Jayson et al., 2008)

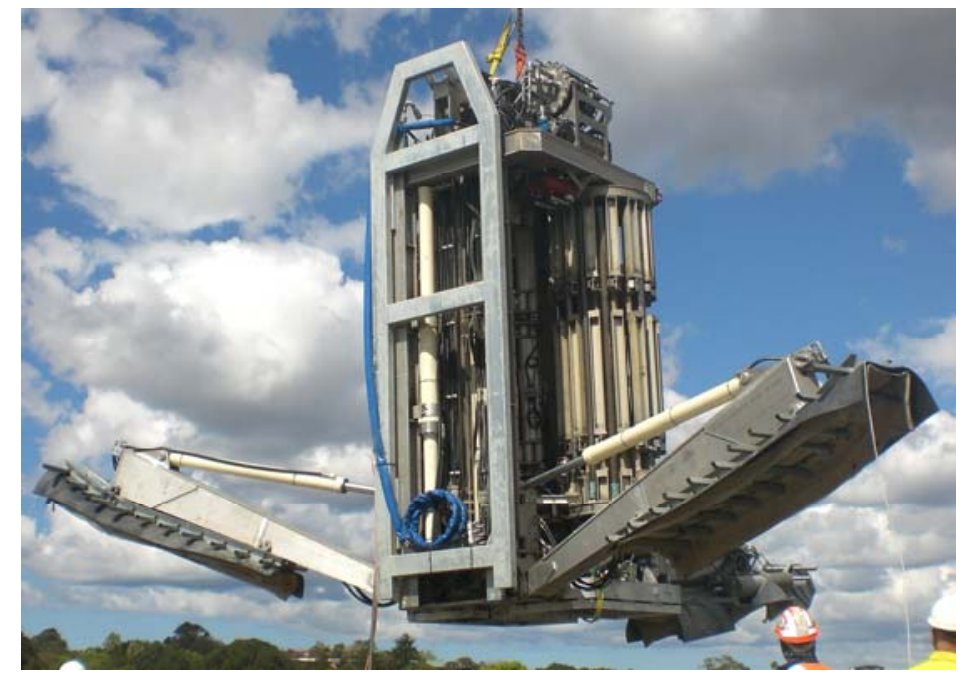

Figure 2 Photograph of the second generation PROD (courtesy Benthic Geotech) 


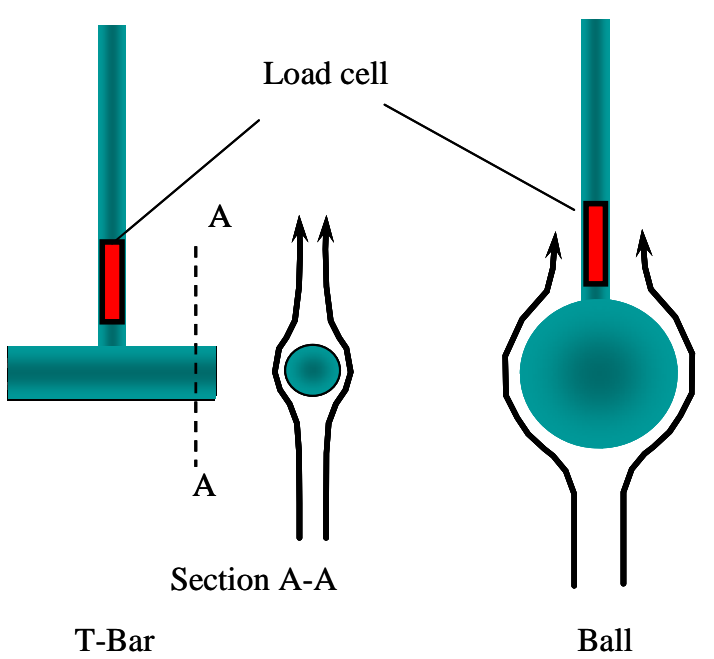

Figure 3 Schematic of T-bar and ball full-flow penetrometers

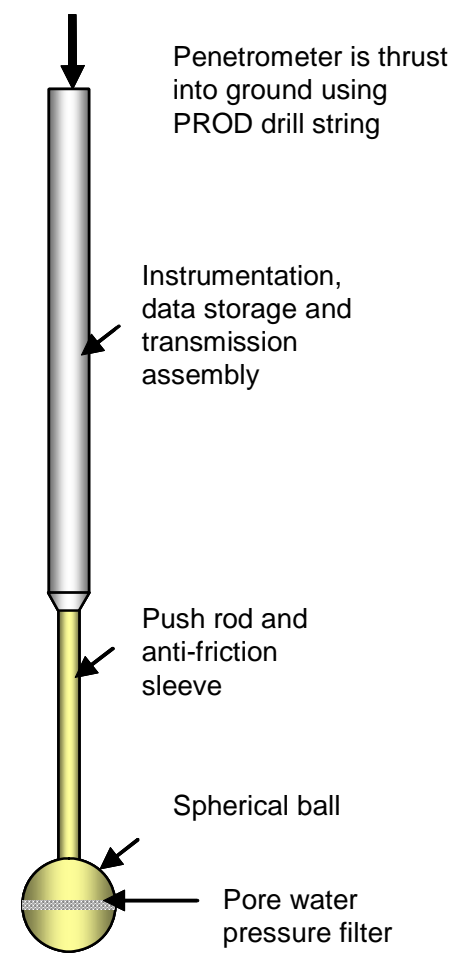

Figure 4 Piezoball penetrometer (Kelleher and Randolph, 2005) 


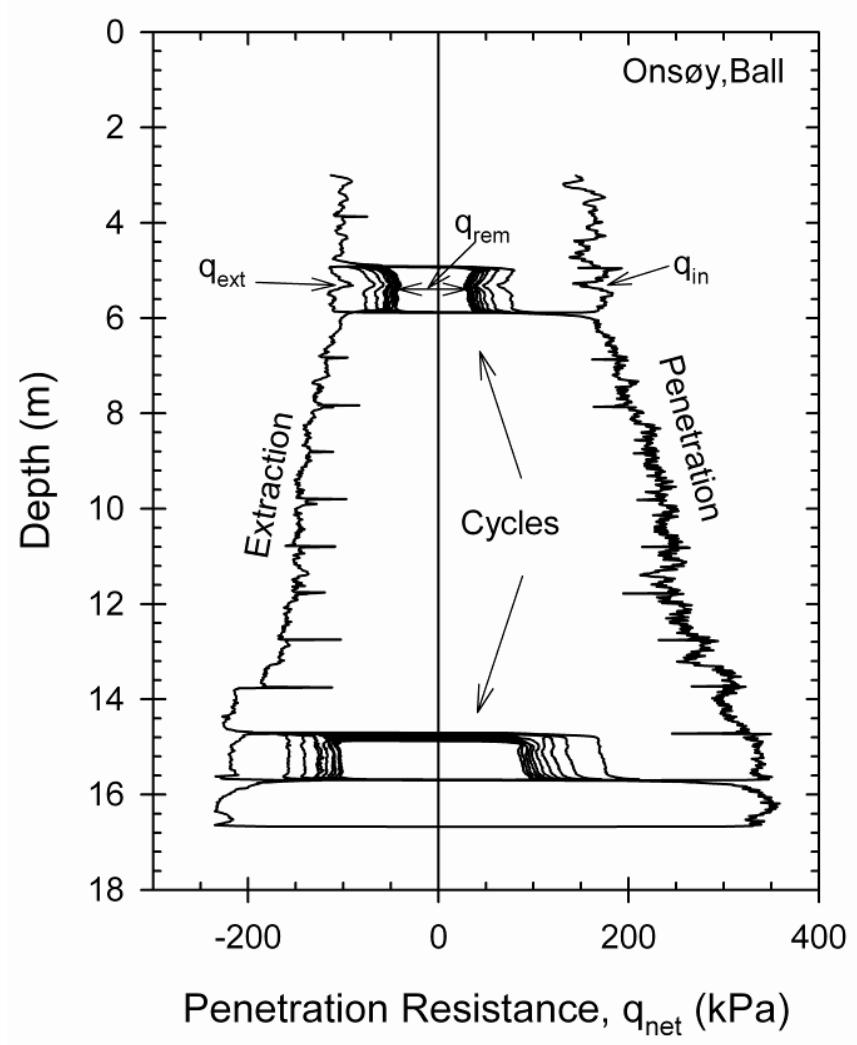

Figure 5 Ball penetrometer penetration and extraction profiles from Onsøy with two cyclic tests (Yafrate et al., 2009)

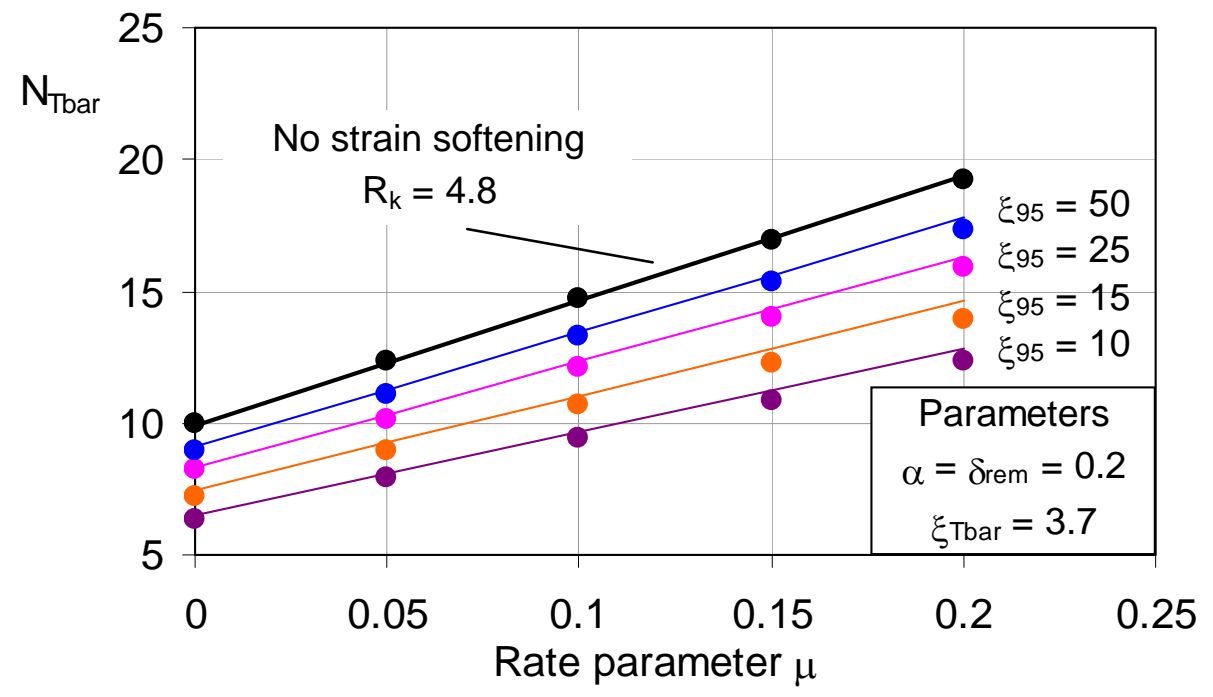

Figure 6 Effects of strain rate dependency and strain softening on T-bar resistance factor (Zhou and Randolph, 2009a) 

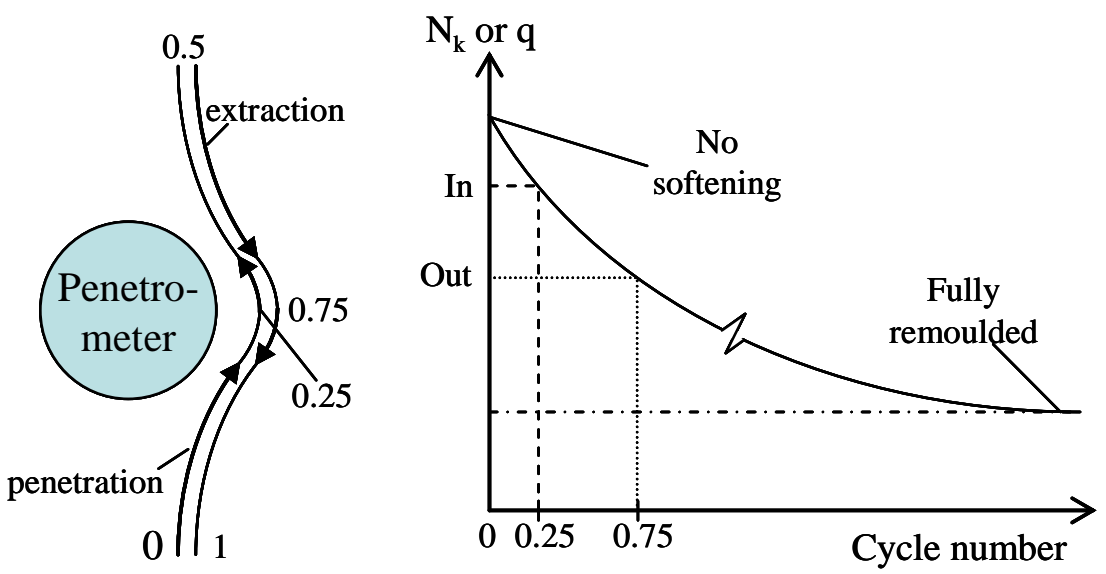

Figure 7 Reduction in soil strength and penetration resistance during cyclic full-flow penetrometer test

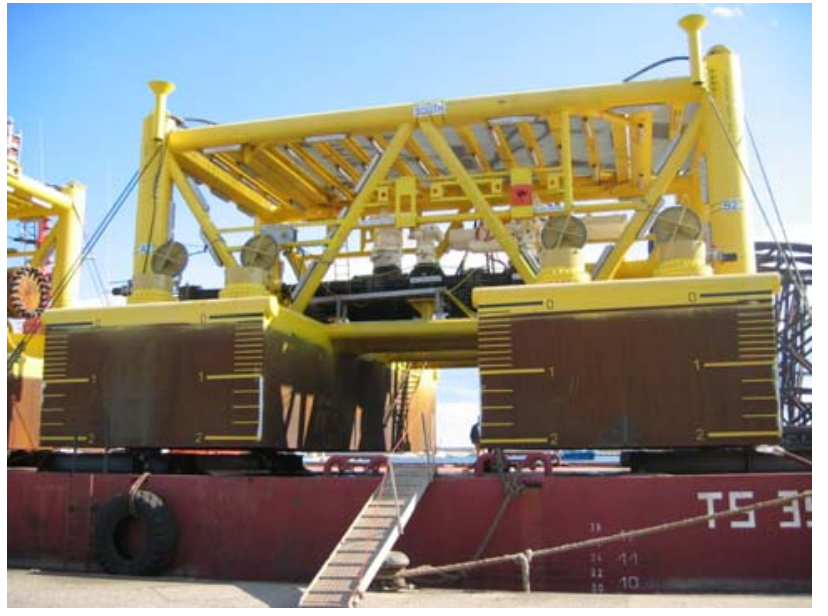

Figure 8 Skirted shallow foundation for subsea facility (courtesy of Ian Finnie, Advanced Geomechanics) 


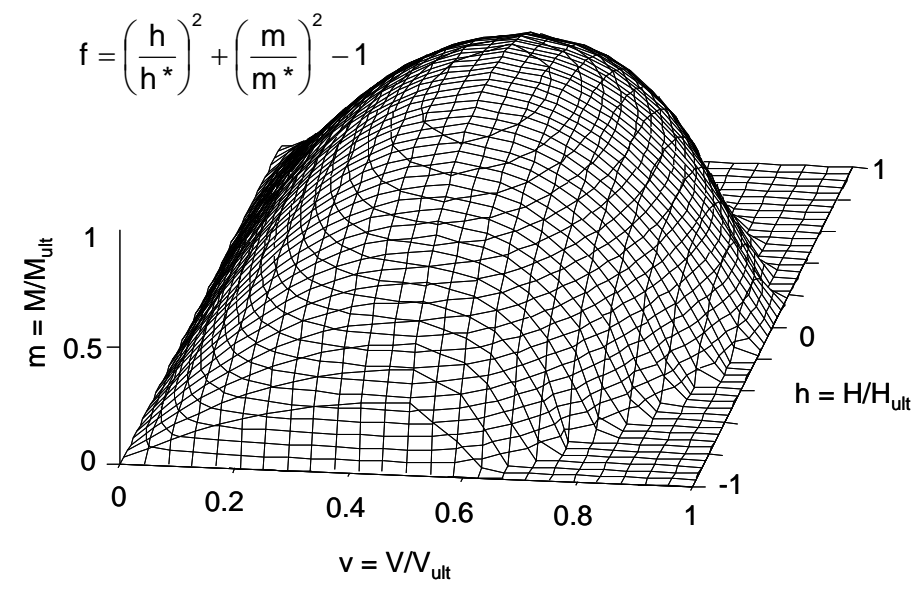

Figure 9 Failure envelope for rectangular surface foundation under general loading (Gourvenec, 2007a)
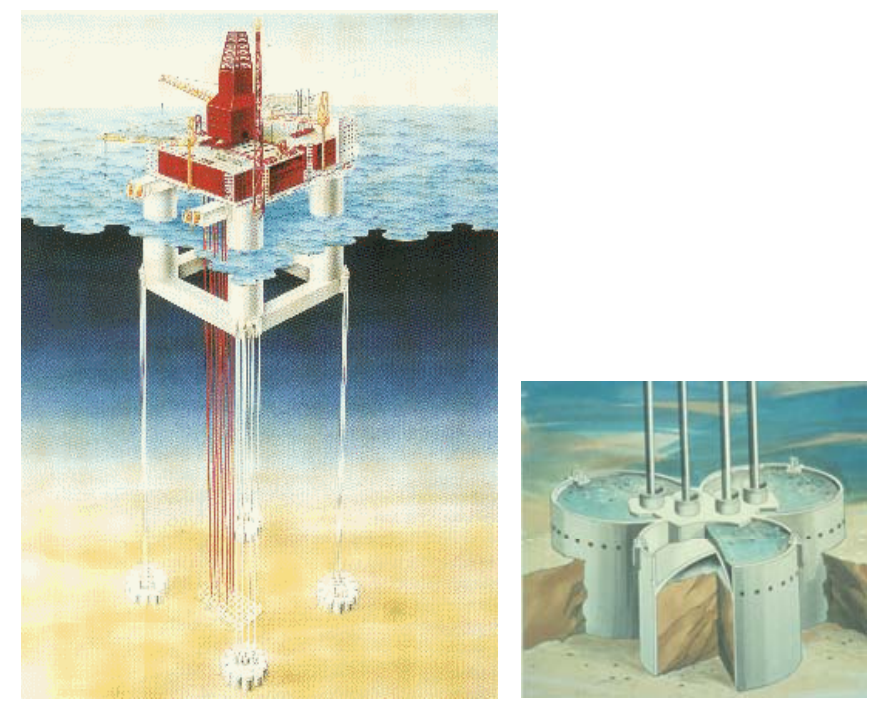

Figure 10 Schematic of the Heidrun TLP and skirted foundations of Snorre A TLP 


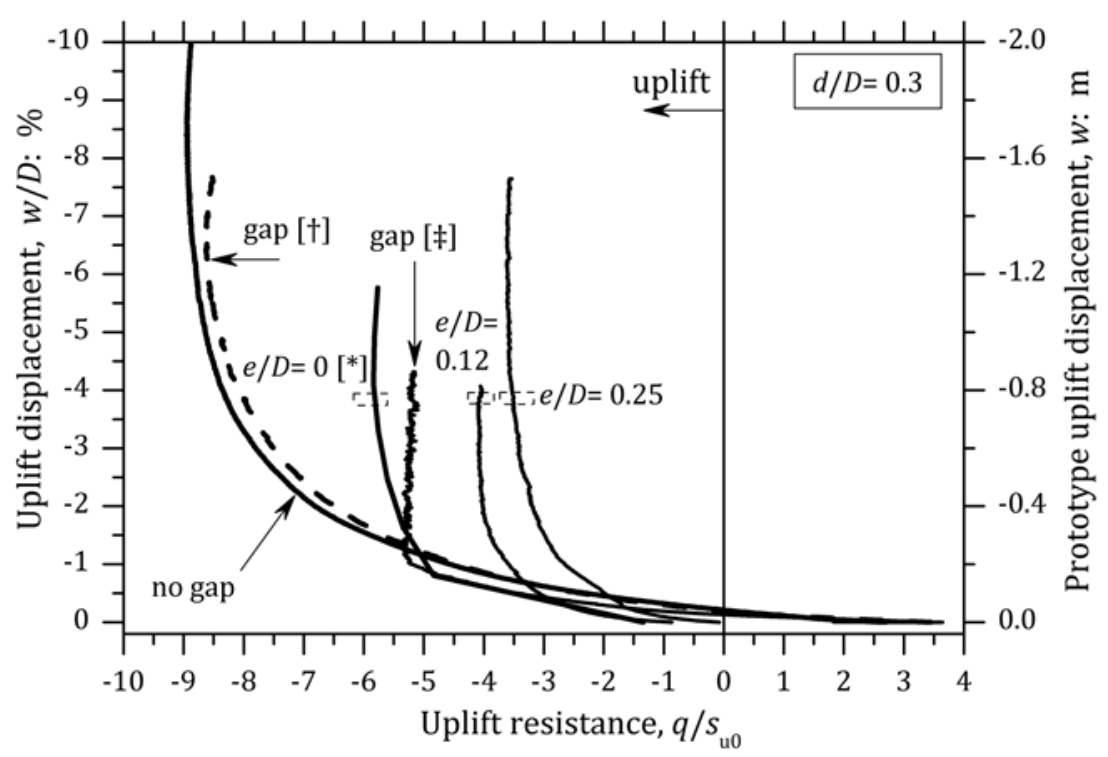

* legend over page

$\uparrow$ uplift immediately following gap formation

‡ uplift following re-consolidation after gap formation

* uplift following displacement controlled consolidation

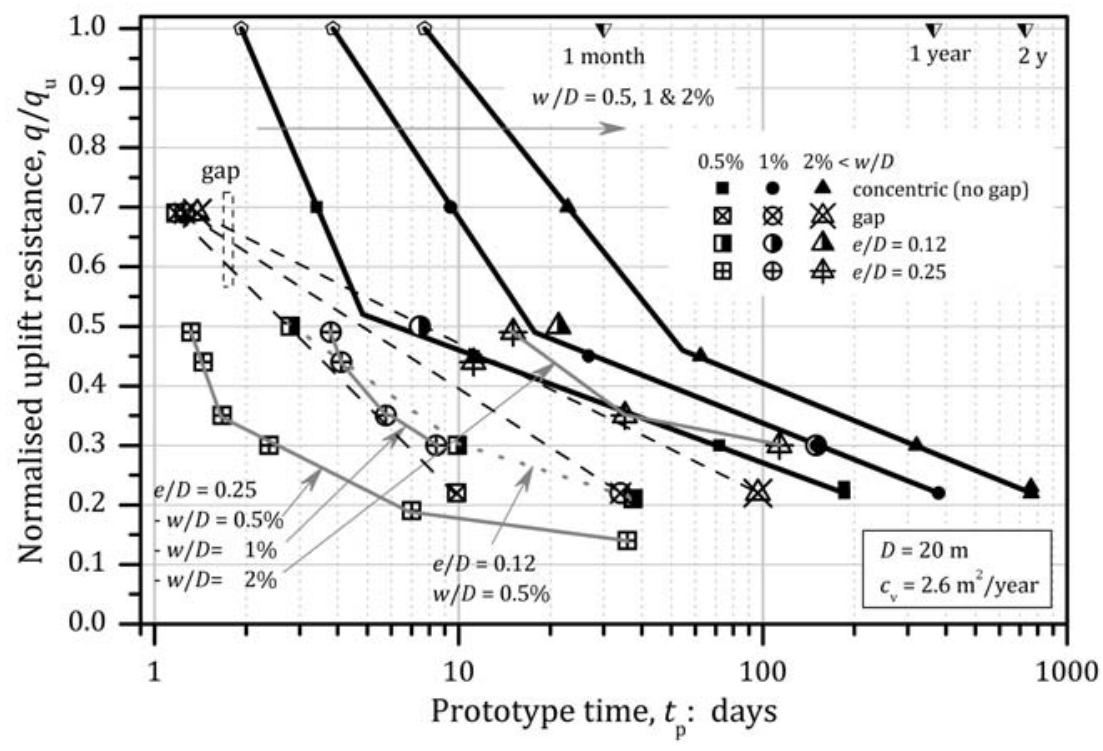

Figure 11 (a) Transient and (b) sustained uplift resistance of a shallow skirted foundation d/D = 0.3 (Gourvenec et al., 2009; Acosta-Martinez et al., 2010) 


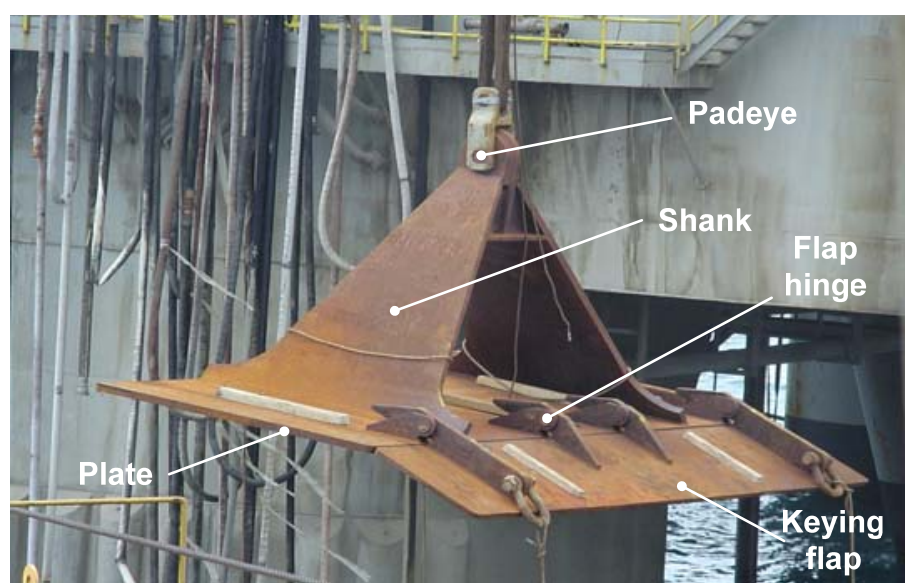

Figure 12. Typical SEPLA with keying flap (Courtesy of ExxonMobil)
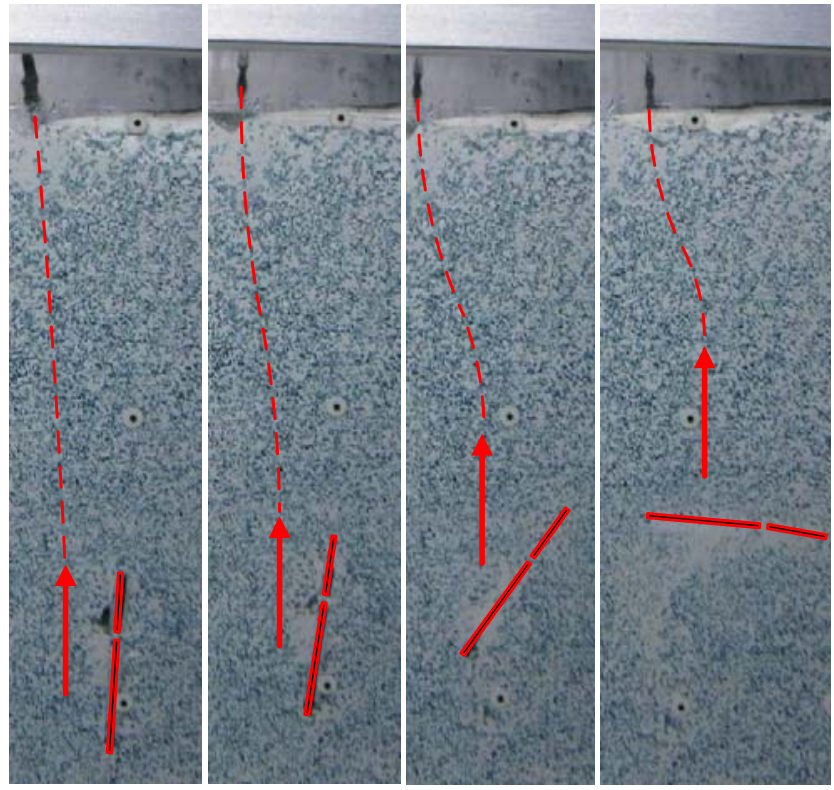

Figure 13. Anchor motion at four different pullout stages during vertical pullout. No activation of the keying flap is observed (after Gaudin et al., 2010c) 


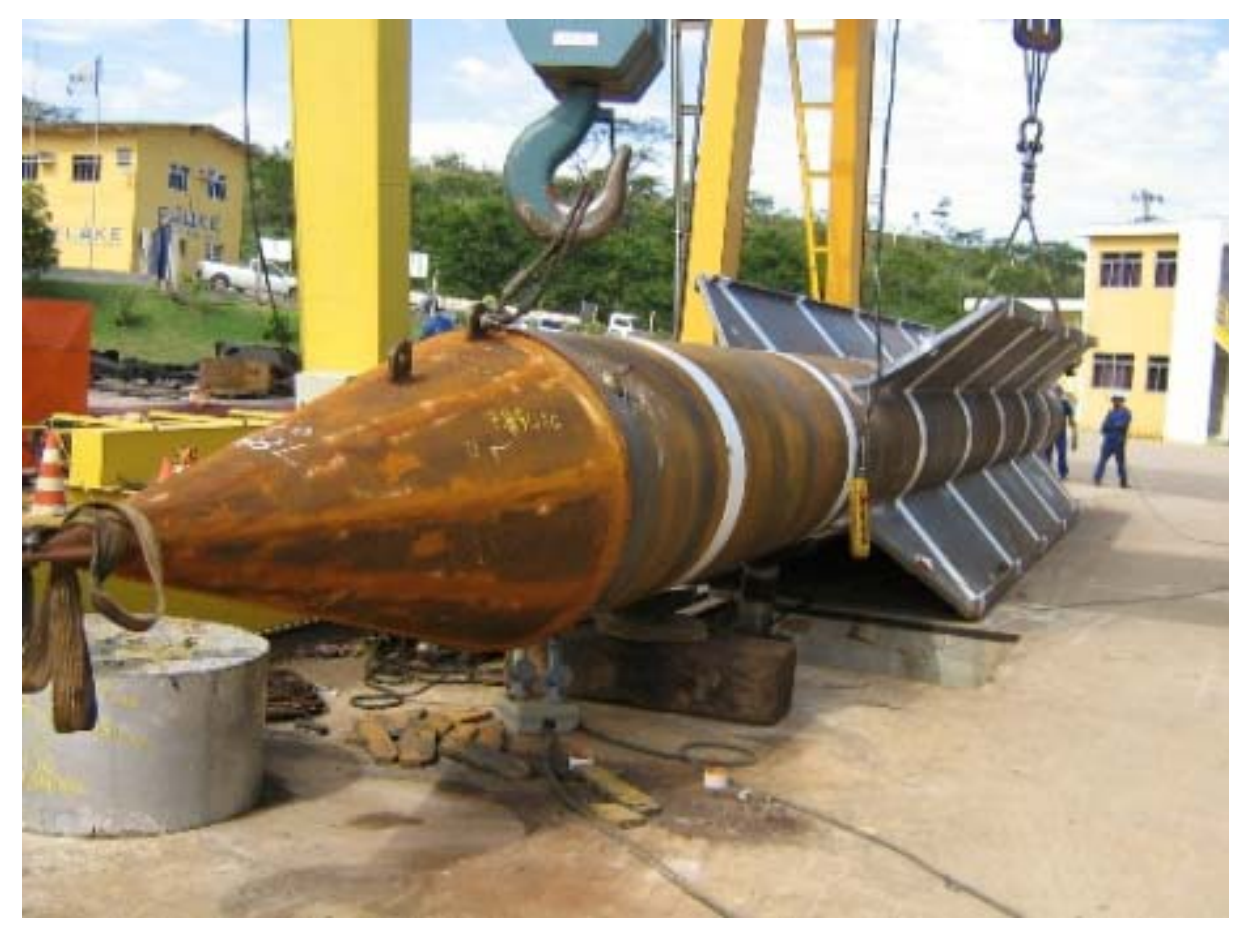

Figure 14. Typical torpedo anchors with four flukes (after de Aguiar et al., 2009)

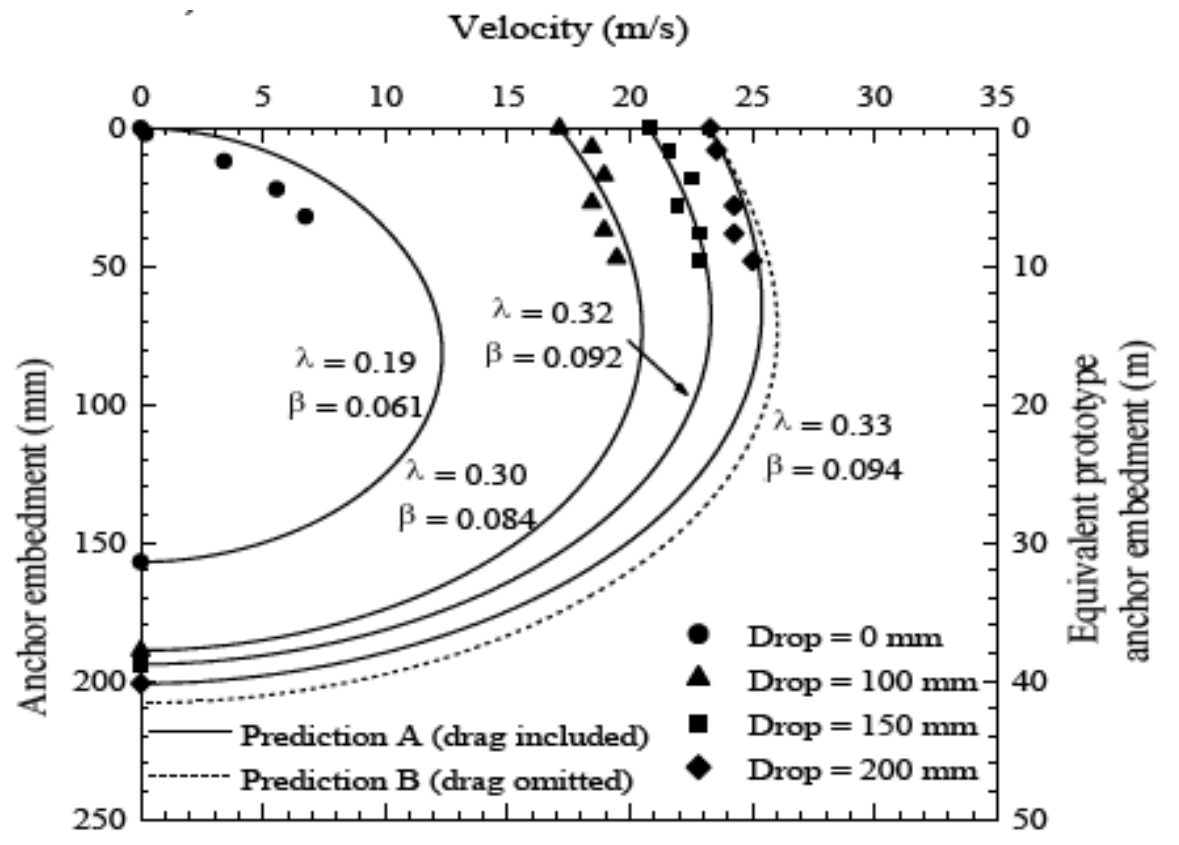

Figure 15. Calibration of embedment model (after O’Loughlin et al., 2009) 


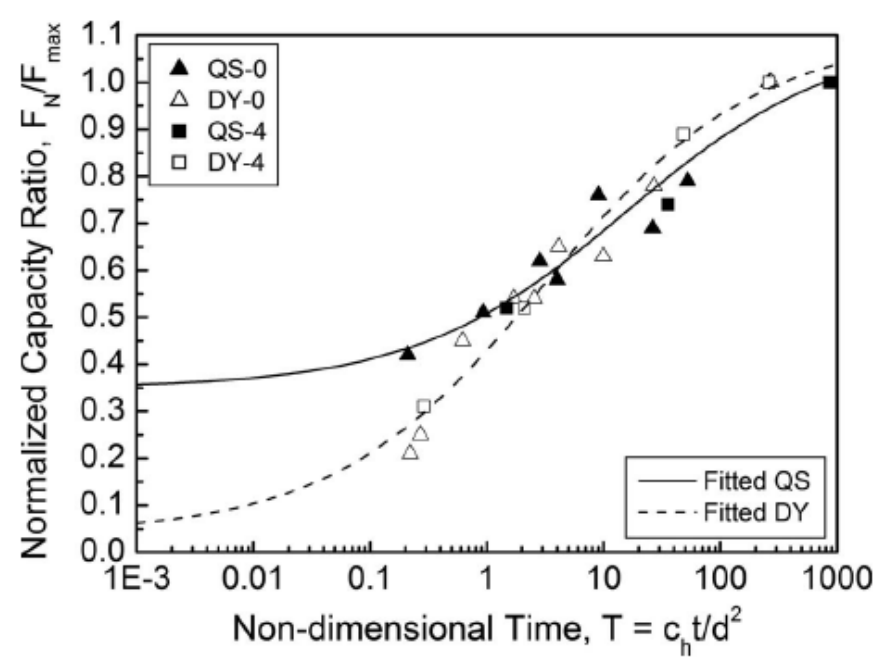

Figure 16. Illustration of the gain in capacity with consolidation time after penetration. QS refers to static installation, DY to dynamic installation (after Richardson et al., 2009)
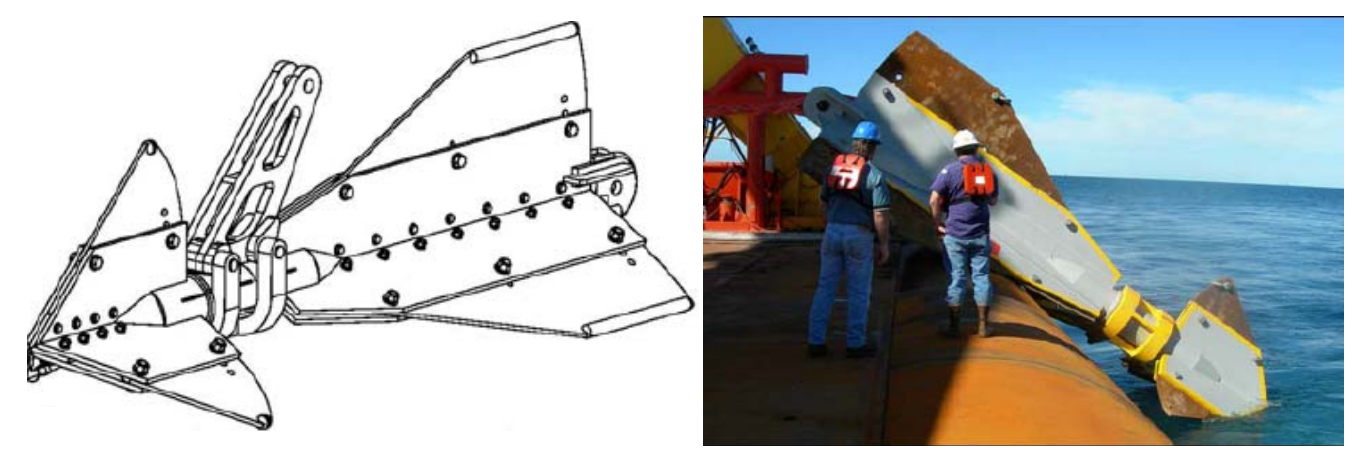

Figure 17. The OMNI-Max anchor (after Shelton, 2007)

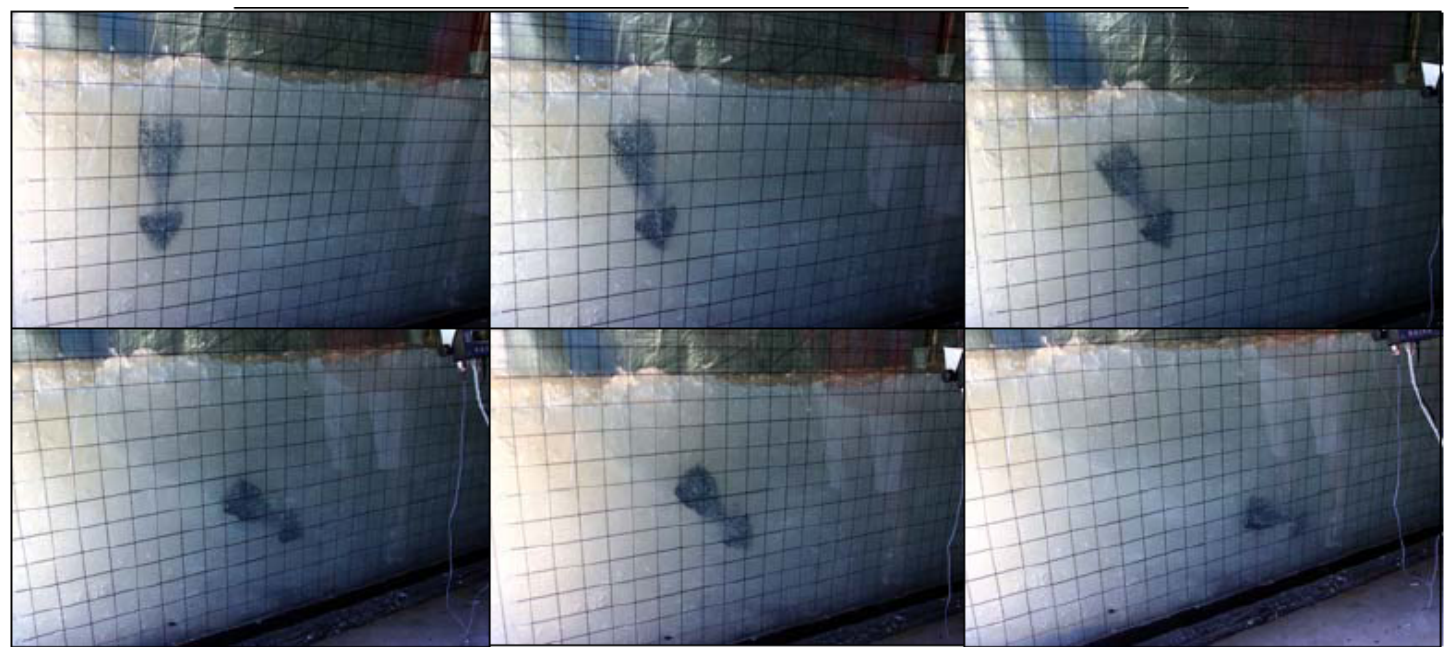

Figure 18. Model OMNI-max anchor in laponite tank laboratory testing. Illustration of the anchor trajectory during loading (after Shelton, 2007) 


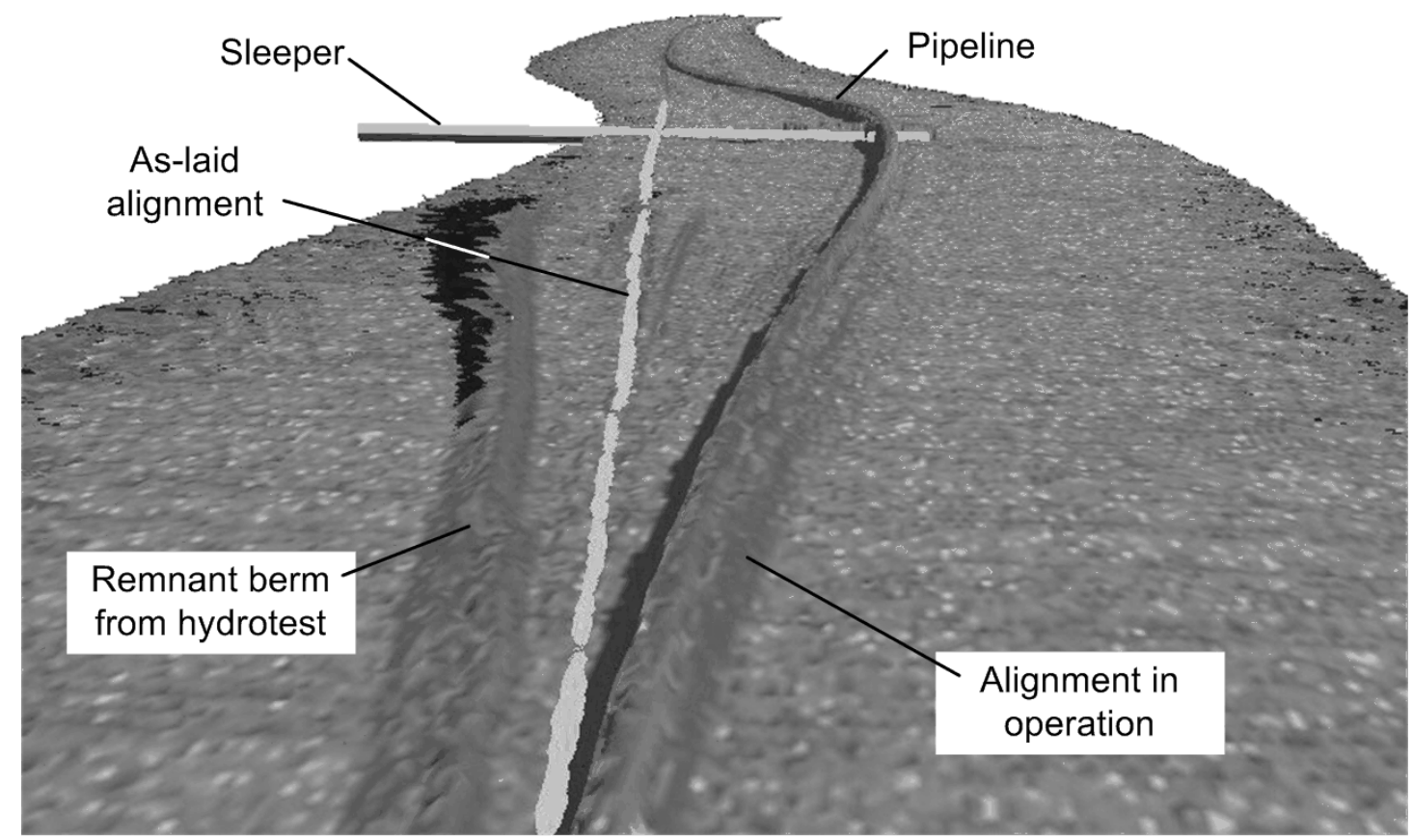

Figure 19 An engineering lateral buckle in a deepwater pipeline (Jayson et al., 2008)
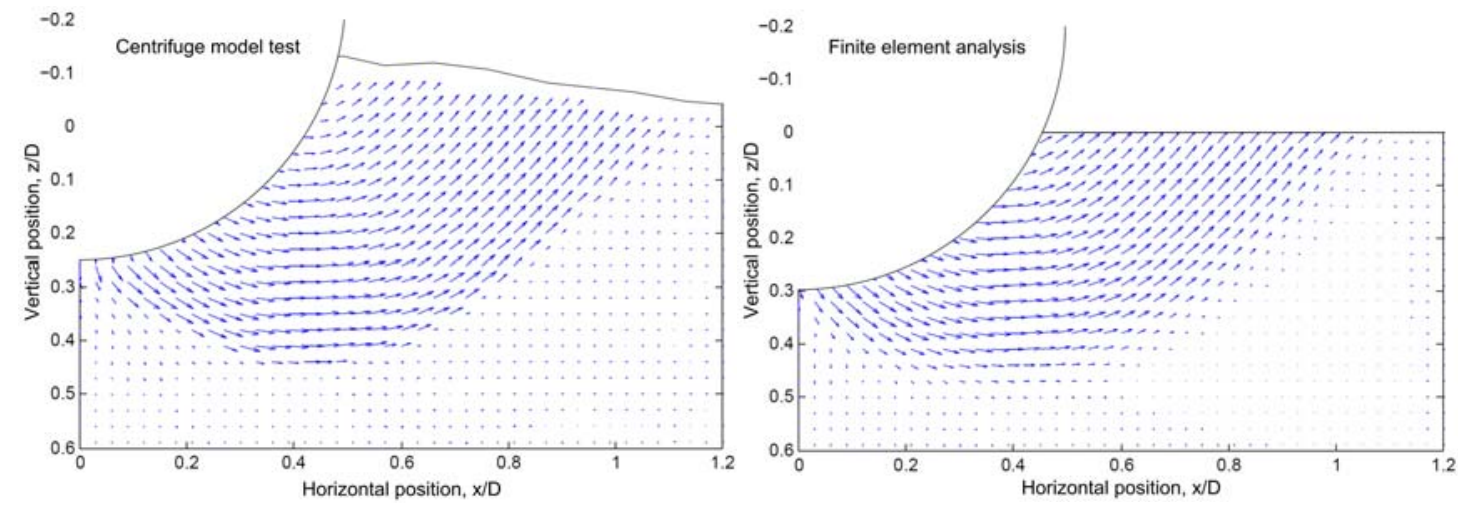

Figure 20 Soil deformation patterns during undrained pipe penetration (a) Physical observations (Dingle et al., 2008) and numerical results (Merifield et al., 2008) 


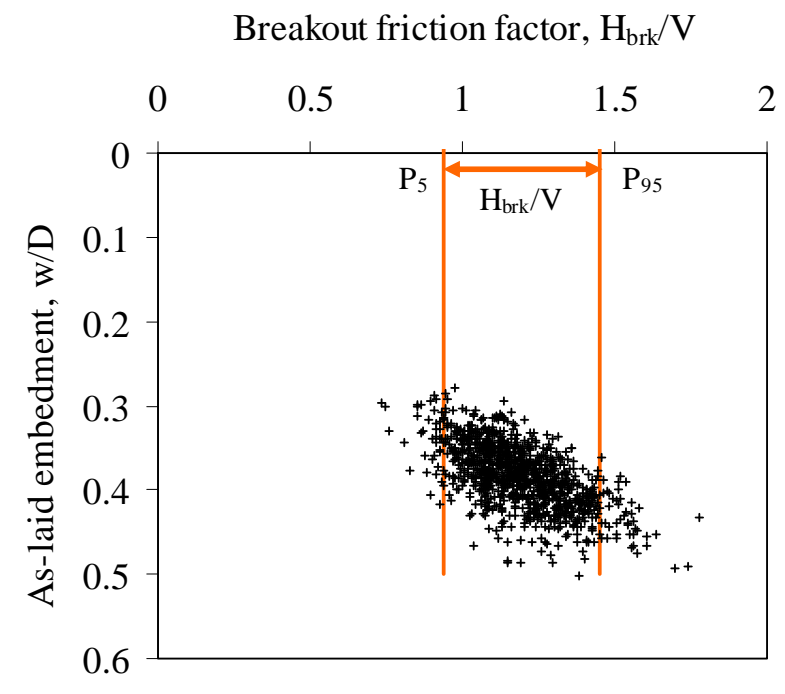

Figure 21 Probabilistic analysis of pipeline embedment and breakout resistance using theoretical failure envelopes (White and Cathie, 2010)
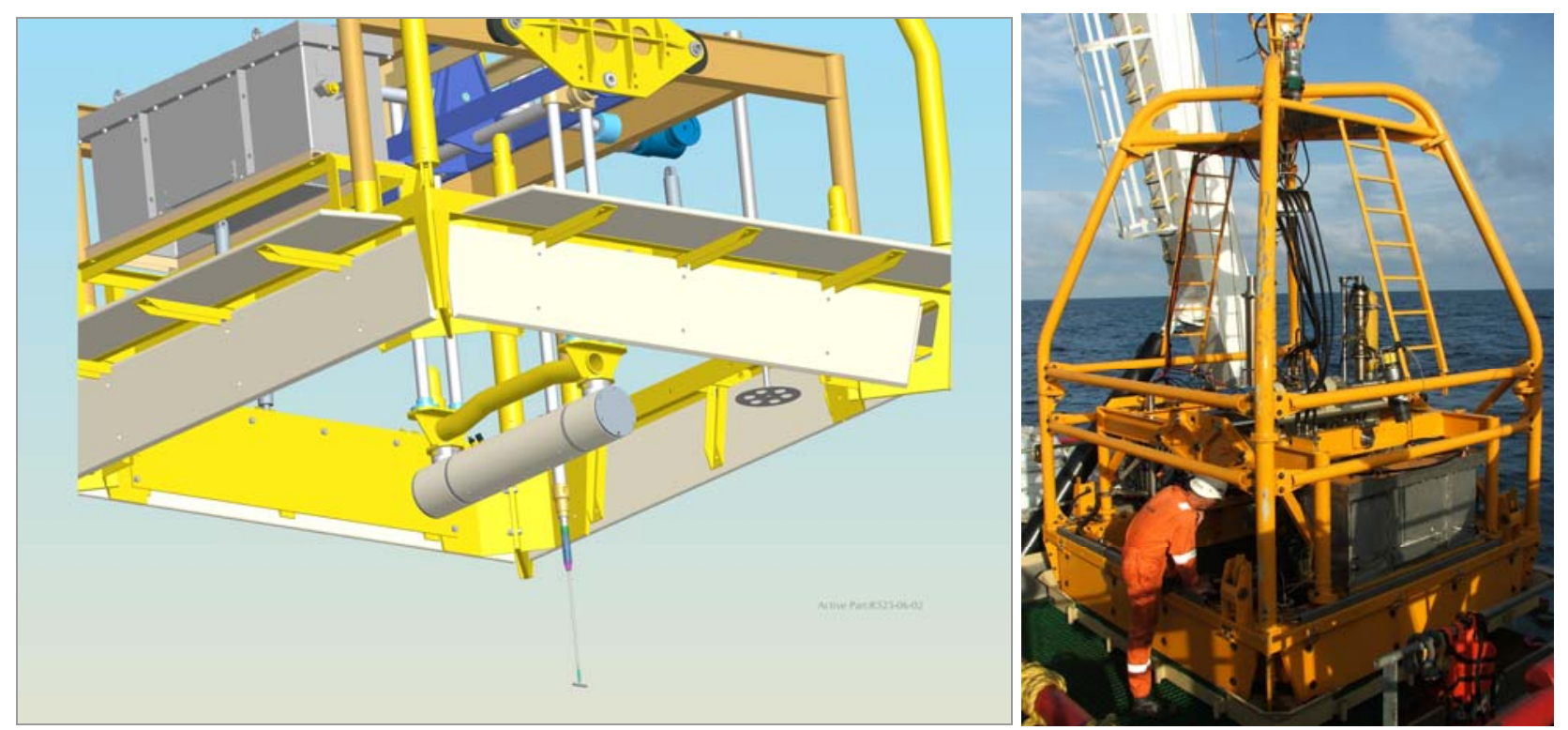

Figure 22 Fugro SMARTPIPE (a) Computer rendering, showing instrumented pipe and miniature T-bar suspended beneath seabed frame (b) Photograph of SMARTPIPE on deck prior to overboarding. (images courtesy of Fugro) 


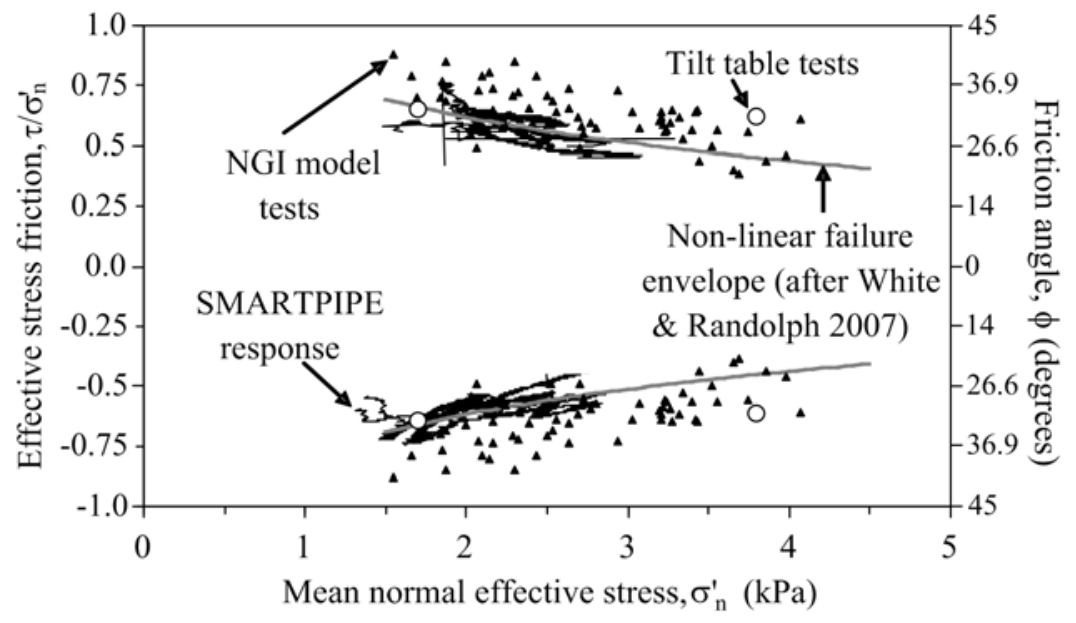

Figure 23 Effective strength of a deepwater clay soil at low stresses (data from Bruton et al., 2009; Hill and Jacobs, 2008; White et al., 2010) 


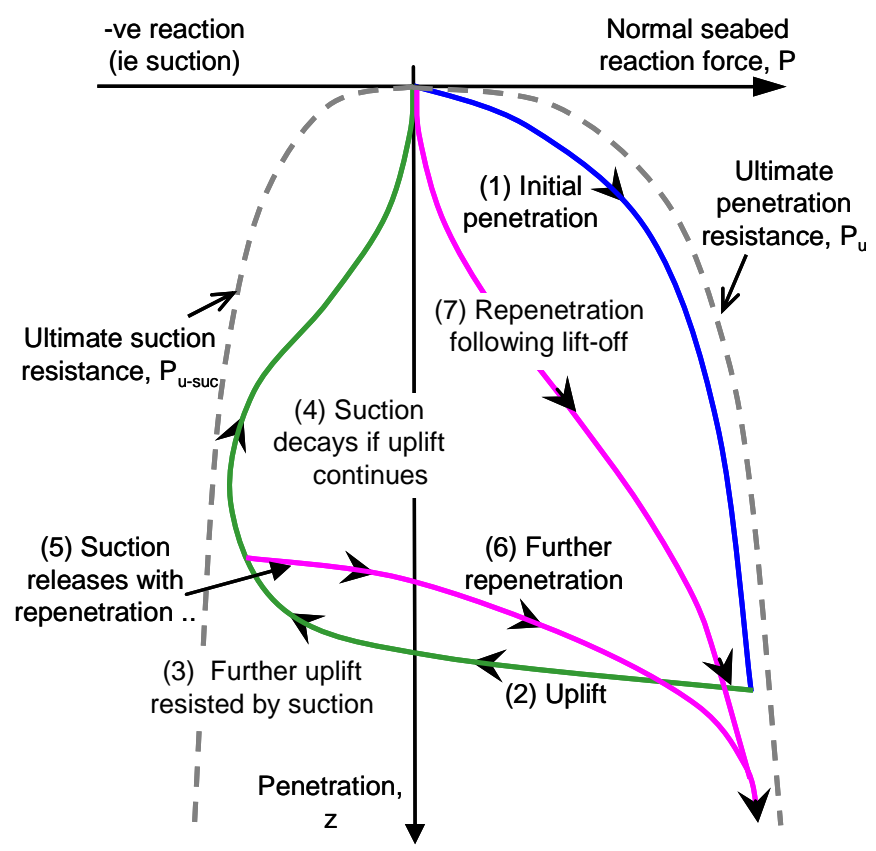

Figure 24 Riser-soil interaction model for different riser motions

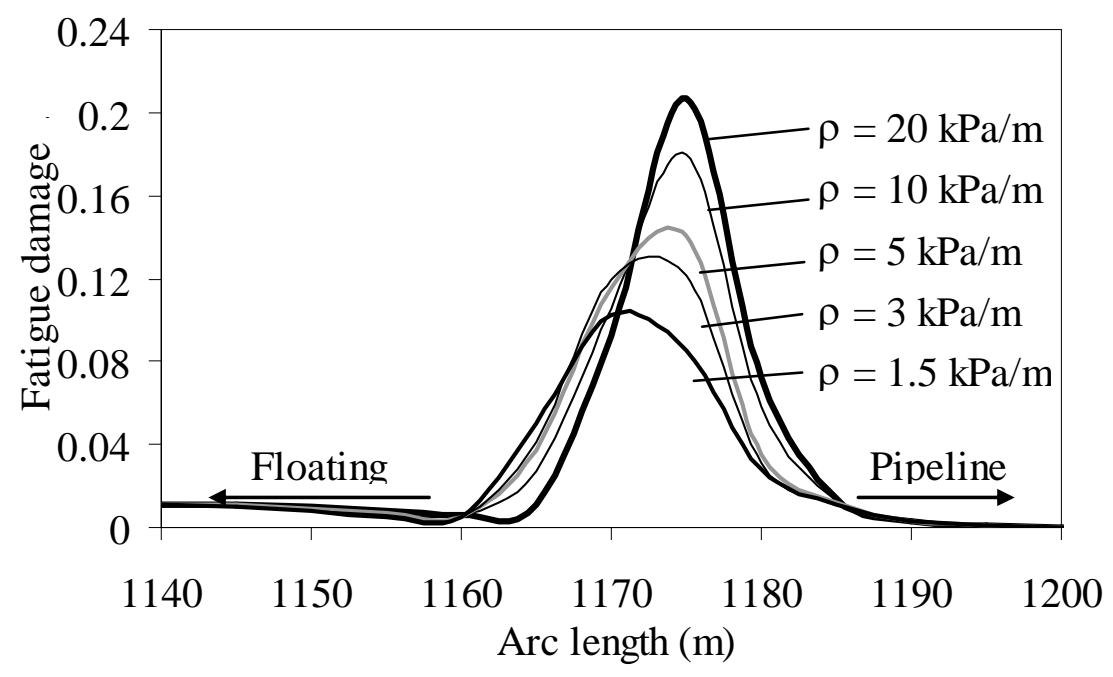

Figure 25 Effect of shear strength gradient, $\rho$, on 20-year fatigue damage 


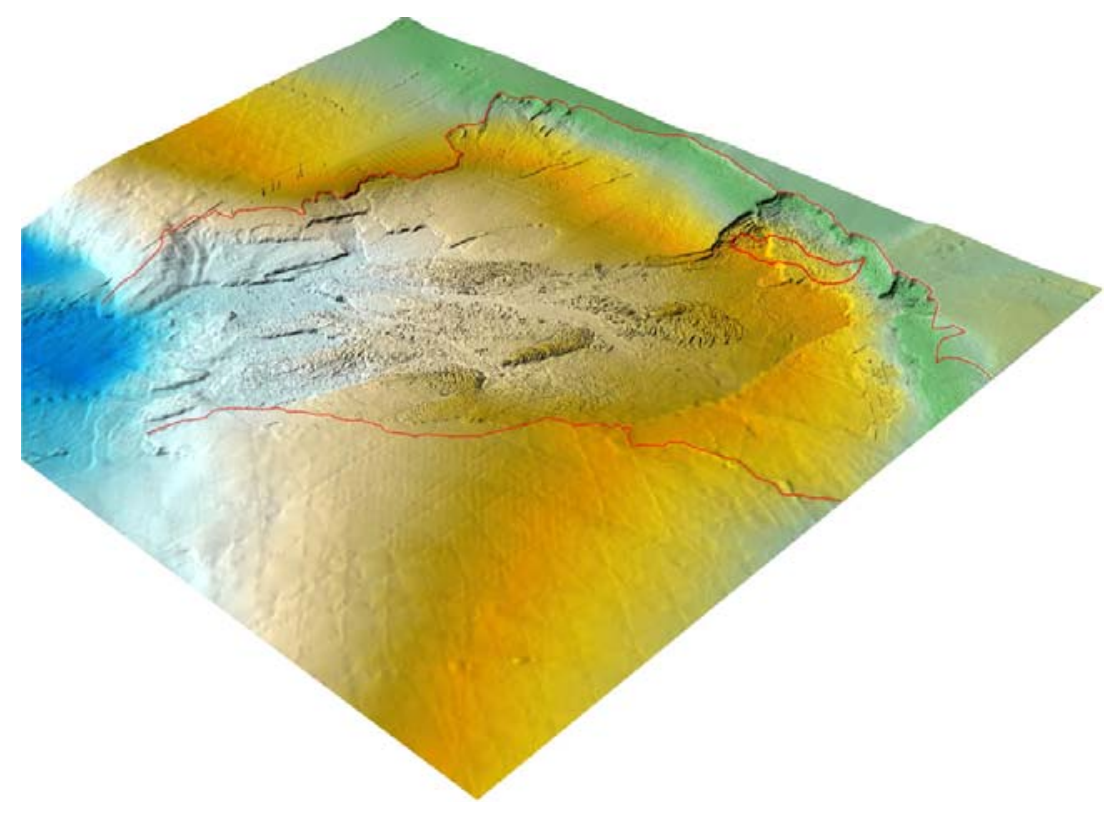

Figure 26 Perspective view of the Storegga slide scar with the Ormen Lange gas field (Andersen et al., 2008)
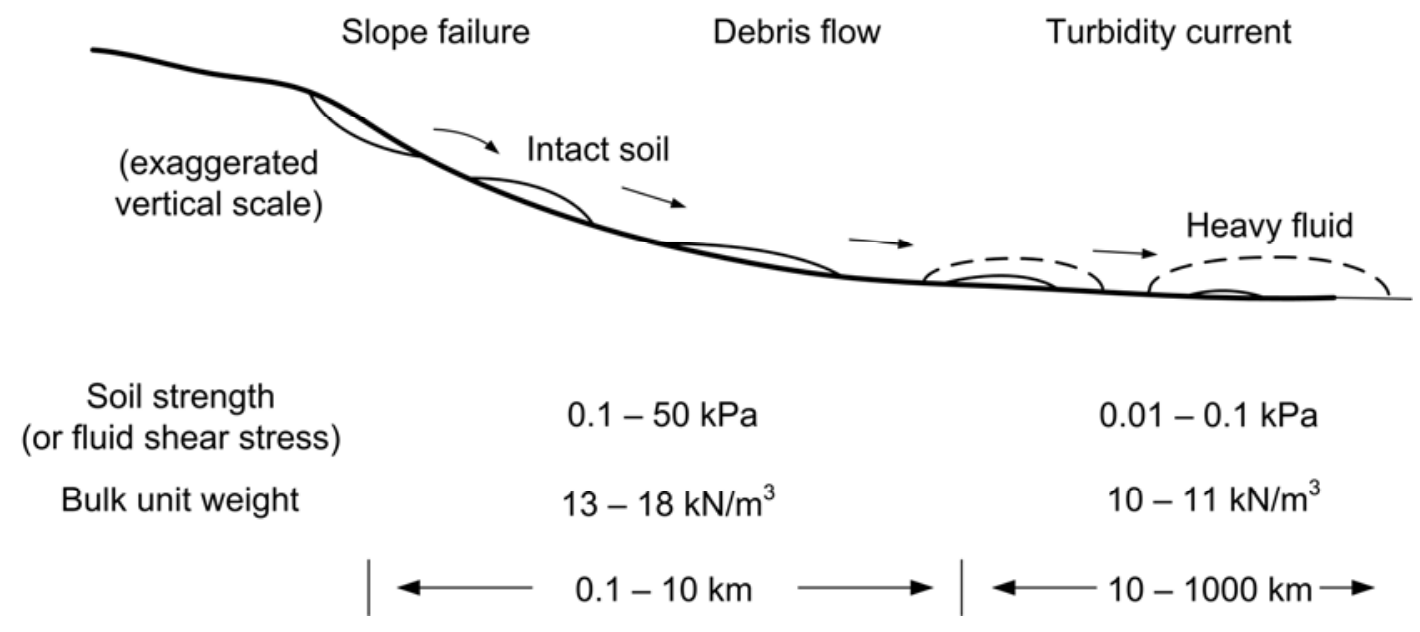

Figure 27 Stages of submarine slide breakdown and typical properties 


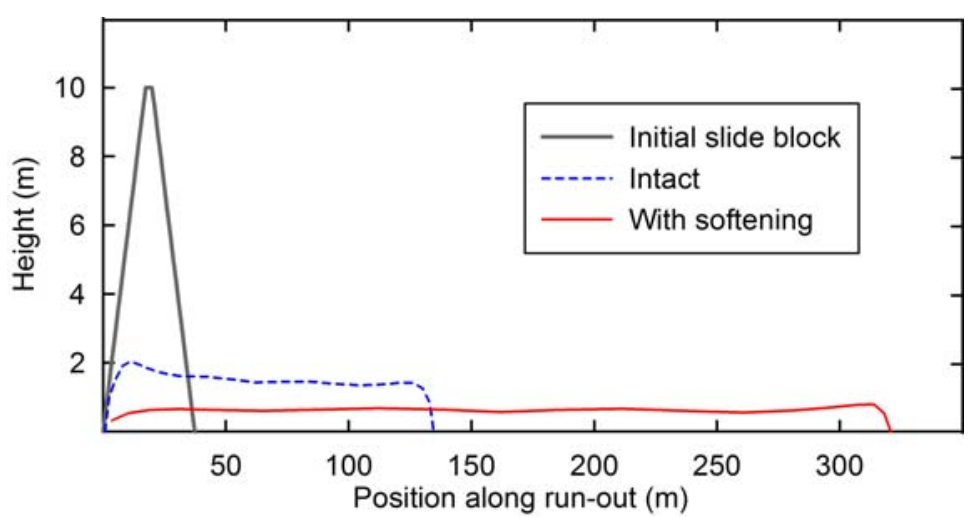

(a)

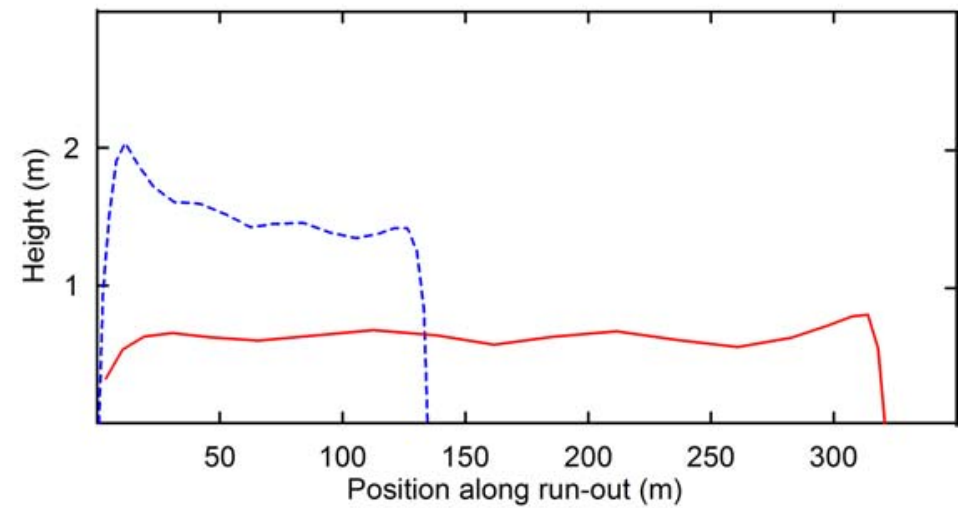

(b)

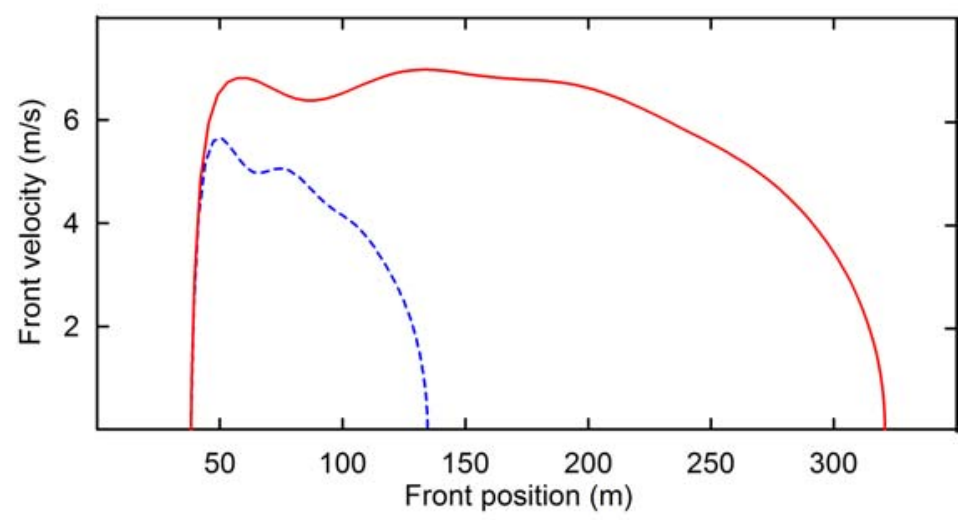

(c)

Figure 28 Example of slide run-out modelled using UWA-SM3 (a) Initial and final profiles; (b) detail of final profiles; (c) front velocity variation during runout 